\title{
New Generations of Spirobifluorene Regioisomers for Organic Electronics: Tuning Electronic Properties with the Substitution Pattern
}

Cyril Poriel, ${ }^{\mathrm{a} *}$ Lambert Sicard, $^{\mathrm{a}}$ Joëlle Rault-Berthelot ${ }^{\mathrm{a}}$

a. Univ Rennes, CNRS, ISCR-UMR 6226, F-35000 Rennes, France.

The spirobifluorene (SBF) fragment constitutes one of the most important scaffold used in the design of Organic Semi-Conductors (OSCs) for organic electronics. For the last ten years, new generations of SBF positional isomers have appeared in the literature. The different positions of substitution (C1, C3 or (4) have allowed the tuning of the electronic properties of great interest for the further design of functional materials. The high potential of these new generations of organic semi-conductors in electronics has been demonstrated notably when used as host for Phosphorescent Organic LightEmitting Diodes (OLEDs) or for Thermally Activated Delayed Fluorescence OLEDs. In the present feature article, we present these new generations of SBF compounds and the impact of positional isomerism on the electronic properties and devices performance. Particularly, we show how the different structural and electronic parameters (nature of the linkages, bridge substitution and steric hindrance) drive the electrochemical and photophysical properties of SBF regioisomers and can be modulated. Such studies lay the foundations of materials design for organic electronics.

\section{Introduction}

Spiro configured compounds constitute one of the most important class of Organic Semi-Conductors (OSCs) for electronics. ${ }^{1-3}$ Since the display of the 'spiro concept' in the nineties by the group of Salbeck, the 9,9'-spirobifluorene (SBF) has become a central molecular scaffold in organic electronics. ${ }^{3,4}$ SBF is the association of two fluorene units via a shared spiro carbon (Figure 1-Left). It possesses a particular 3D geometry with the two fluorene units set along two orthogonal planes. One of the particularity of the SBF fragment is its capacity to improve the thermal and morphological properties of the OSC in which it has been introduced. ${ }^{2}$ Therefore, the SBF scaffold is found in many highly efficient OSCs especially for Organic Light-Emitting Diodes (OLED) as a fluorophore ${ }^{5}$ or as high triplet host material for phosphors. ${ }^{6}$ In the field of solar cells, the SBF fragment also played a key role as the widely known 2,2',7,7'-Tetrakis[N,N-di(4methoxyphenyl)amino]-9,9'-spirobifluorene (Spiro-OMeTAD), used as hole transporting material, is constructed on a SBF core. $^{7-9}$ New electronic applications taken advantages of the cross-shape geometry of the SBF fragment have also started to appear in the literature such as non-fullerene acceptors in solar cells, ${ }^{10-13}$ spiro-fused nanographene structures ${ }^{14}$ or ordered monolayers. ${ }^{15,16}$

Thanks to this singular geometry, the SBF scaffold has also been investigated for other appealing applications outside of organic electronics such as fluorescent marker for biomolecules, ${ }^{17}$ chiral ligands, ${ }^{18,19}$ catalysts in homogeneous ${ }^{20,}$ 21 or heterogeneous ${ }^{21-24}$ chemical reactions (epoxidation, sulfoxidation...), or as building units in coordination polymers, ${ }^{25}, 26$ showing the versatility of this platform. In all these examples, it is the 3D geometry of the SBF scaffold that has been taken advantage of. The substitution pattern of SBF has been far less studied and it is the main purpose of the present feature article.

In the SBF fragment, sixteen substitution positions are available, 4 on each phenyl unit numbered from 1 (in $\beta$ position of the spiro carbon) to 4 (in $\alpha$ position of the biphenyl linkage), Figure 1-Left. 2-Substituted SBFs were the first generation to be developed, ${ }^{2}$ due to an easier synthetic access compared to the other positional isomers. Indeed, the direct aromatic electrophilic substitution of the SBF core takes place at $\mathrm{C} 2$ and this type of reaction has been a precious tool to develop 2-substituted SBFs. The para linkage between the pendant substituent at $\mathrm{C} 2$ and the constitutive phenyl rings of the fluorene ensures a good delocalization of $\pi$-electrons, essential to create efficient fluorophores. ${ }^{2-5}$ However, in recent years, the growing necessity to design efficient host materials for blue Phosphorescent Organic Light-Emitting Diodes $(\text { PhOLED })^{27,28}$ has led to a demand of new generations of SBFbased materials with wide energy gaps (ca $4 \mathrm{eV}$ ) and hence a restricted $\pi$-conjugation. Indeed, in order to obtain a high triplet energy $\left(E_{T}\right)$, a key feature in the design of host materials for blue PhOLEDs (which are still the weakest link of this technology), ${ }^{29}$ the $\pi$-electrons delocalization within the OSC has to be restricted. This $\pi$-conjugation disruption has been successfully investigated with ortho linked SBFs (substitution at position $\mathrm{C}_{4}{ }^{3,}{ }^{30-35} 5$ first example reported in 2009) and meta linked SBFs (substitution at position C3-first example reported in 2013 or at position C1-first example reported in 2017), ${ }^{36-39}$ leading to high-efficiency green and blue PhOLEDs. However and despite these recent high-performing devices, only few examples of 1-, 3- and 4-substituted SBFs have been described to date. Nevertheless, they possess great potential.

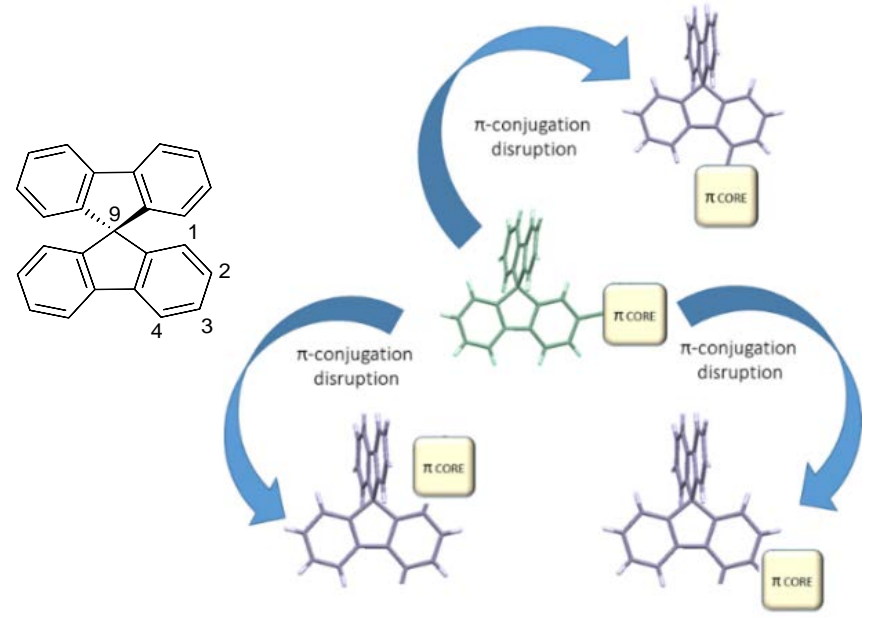

Figure 1. Nomenclature of SBF (Left) and schematic representation of the SBF substitution positions (Right).

In May 2017, the first structure-property relationship study covering the four positional isomers of SBF was reported by 
our group. ${ }^{39}$ This work has not only highlighted the strong effect of the substitution pattern on the electronic properties but has also revealed the potential of the position C1 for electronic applications. In March 2019, the efficiency of the C1 position to construct high $E_{\mathrm{T}} \mathrm{SBF}$-based host materials was demonstrated, leading to the highest performance ever reported for pure hydrocarbon hosts in blue PhOLEDs. ${ }^{6}$ This important finding has motivated the present review. Herein, we aim to overview these new generations of SBF isomers substituted at C1, C3 or C4 and the effect of the substitution pattern in modulating their electronic properties. As regioisomerism is an important concept, which drives the properties of OSCS and their resulting device performance, ${ }^{1,39-}$ ${ }^{43}$ the goal of this work is to define the general rules of SBF regioisomerism in order to help the rational design of future functional materials for electronics.

In the present article, we will first focus on the general synthetic routes, which have been developed over the last years to access these new generations of SBF regioisomers. Then, through a structure-property relationship approach (exemplified with the four phenyl SBF isomers), we will describe the impact of regioisomerism on the electronic properties (electrochemistry, absorption, fluorescence, phosphorescence). Finally, selected examples of OSCS belonging to each family of SBF (substituted either at C4, at C3 or at C1) will be discussed. The potential of these OSCs as host materials for PhOLEDs or for Thermally Activated Delayed Fluorescence (TADF) OLEDs will also be highlighted. Thus, in the present work, we discuss how the different structural and electronic parameters (nature of the linkages, bridge substitution and steric hindrance) drive the electronic properties of SBF regioisomers. Such studies lay the foundations of materials design for organic electronics.

In order to well describe the impact of the substitution of the SBF core, this review will only focus on monosubstituted SBFs.

\section{Part 1. Synthetic Investigations}

To date, SBF compounds substituted at $\mathrm{C} 2$ have been far more developed than those substituted at the three other positions. A review was published by Salbeck and coworkers in $2007{ }^{2}$ Indeed, incorporation of a molecular fragment at positions C1, C3 or C4 of a SBF backbone is far more complicated than at position C2 since the direct electrophilic substitution of SBF does regioselectively occur on the latter. ${ }^{2}$ This fact has hindered the development of $\mathrm{C} 1, \mathrm{C} 3$ or $\mathrm{C} 4$ positional isomers. However, the last ten years have led to the development of efficient synthetic routes towards these regioisomers, which are at the origin of the rise of these materials in organic electronics. In this context, the halogeno derivatives hold an important place and the 1-, 2-, 3- and 4-bromo-9,9'spirobifluorenes (1-Br-SBF, 2-Br-SBF, 3-Br-SBF and 4-Br-SBF) are the cornerstone of all the substituted SBFs reported to date.

First reported in $1930,{ }^{44}$ SBF is classically obtained in a twostep synthesis from the coupling of 2-halogenobiphenyl (1 or 2) and 9-fluorenone 3 followed by an intramolecular cyclization of the resulting fluorenol to form the spiro bridge. The synthesis of 1-Br-SBF, 3-Br-SBF and 4-Br-SBF platforms is based on the introduction of the bromine atom before this key cyclization step. Theoretically, the introduction of the bromine atom can be done either on the electrophile (fluorenone) or on the nucleophile (biphenyl). However, incorporating the bromine atom on the nucleophile is difficult and has only been performed in the case of 4-Br-SBF (see below).

Thus, the approach towards bromo-spirobifluorenes (1-Br-SBF, 2-Br-SBF, 3-Br-SBF and 4-Br-SBF (Scheme 1) consists in fixing the bromine atom on the fluorenone core prior to the final cyclization. This route involves the synthesis of the
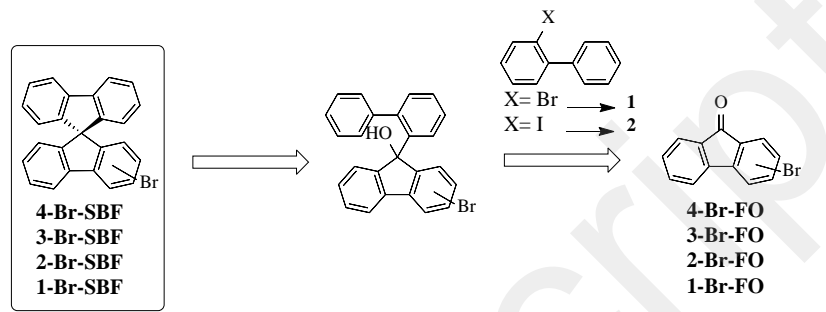

corresponding fluorenones substituted either at C1 (1-Br-FO), C2 (2-Br-FO), C3 (3-Br-FO) or C4 (4-Br-FO). As 2-Br-SBF and its corresponding fluorenone 2-Br-FO have been largely reported in the literature, ${ }^{2}$ they will not be described herein and we will only focus on the three other regioisomers.

Scheme 1. Retrosynthetic analyses of bromo-spirobifluorenes

\section{1.a. Synthesis of 4-Br-SBF and 4-substituted SBFs}

Firstly, in the case of 4-Br-SBF, the fluorenone 4-Br-FO was reported by a selective Miyaura-Suzuki cross coupling between 2-ethyl carboxylate phenylboronic acid $\mathbf{5}$ and 2-bromoiodobenzene $\mathbf{4}$ followed by an intramolecular aromatic electrophilic cyclization of the resulting biphenyl 6 (Scheme 2$)^{32}$ The anchoring of a spiroconnected fluorene unit on 4-Br-FO using bromobiphenyl 1 leads to the fluorenol 7, which finally provides 4-Br-SBF after an intramolecular ring closure step.

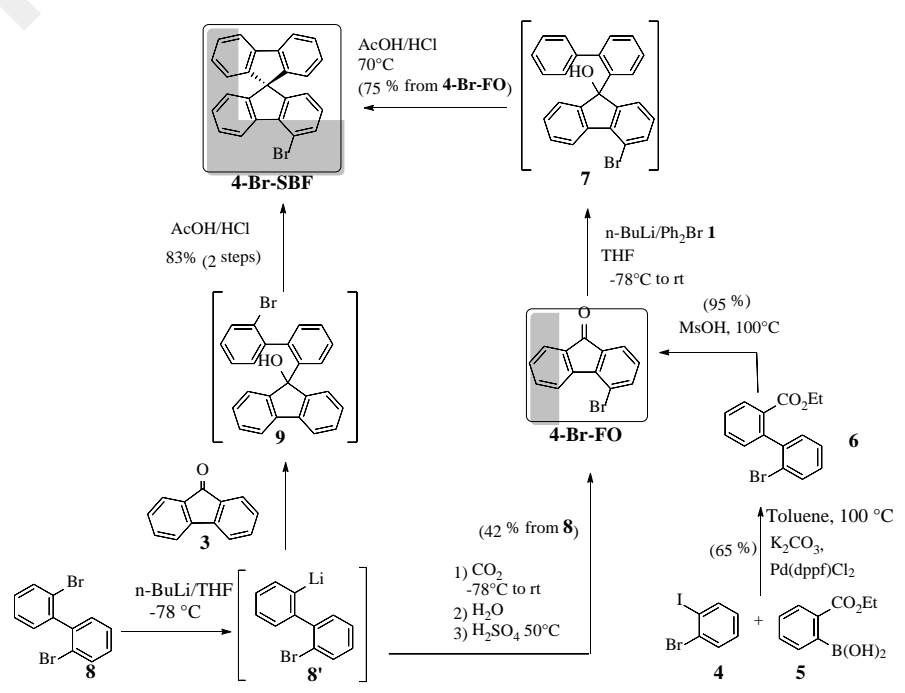

Scheme 2. Synthesis of 4-Br-SBF and 4-Br-FO

In 2009, the group of Ma also reported the synthesis of the key building block 4-Br-FO thanks to a mono lithium-halogen exchange of 2,2'-dibromobiphenyl $\mathbf{8}$ followed by the trapping of the corresponding lithiated intermediate $\mathbf{8}^{\prime}$ with carbon dioxide (Scheme 2). ${ }^{31}$ Secondly and as mentioned above, the bromine can also be attached to the nucleophile (ie the biphenyl). Thus, the trapping of the mono-lithiated intermediate $\mathbf{8}^{\prime}$ can be done with $\mathbf{3}$ 
directly providing 4-Br-SBF after cyclization of the fluorenol intermediate 9. ${ }^{31}$ Most of the 4-substituted SBFs reported in literature were synthesized from 4-Br-SBF or its pinacol analogue 4pinacolborane-SBF. They will not all be reported herein as they are covered by an exhaustive review published in 2017. ${ }^{3}$ They incorporate many different functional units such as electron- or hole-transporting fragments (Scheme 3), which allow to adjust molecular orbitals and to use 4-substituted SBFs as functional materials in electronic devices (see Part 3).
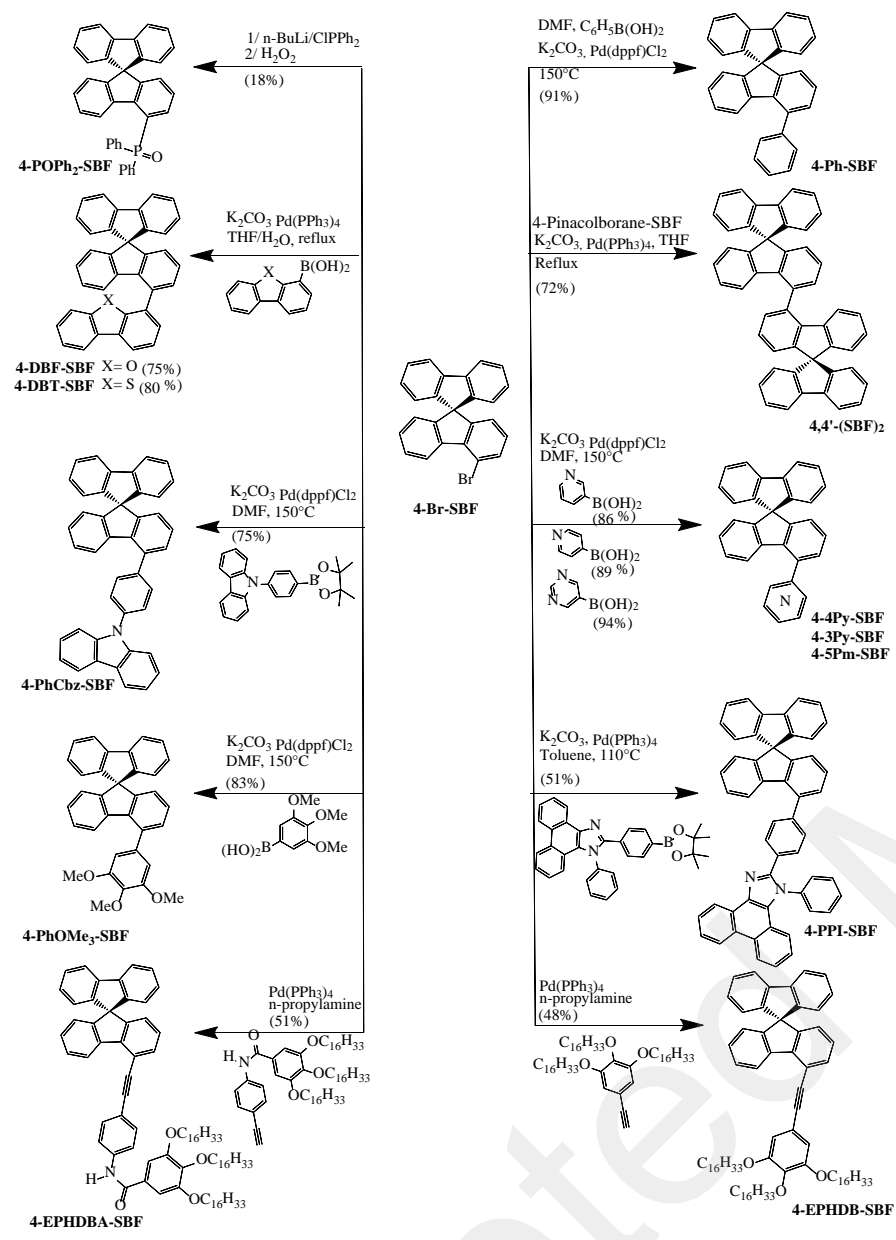

Scheme 3. Synthesis of selected examples of 4-substituted SBFs from 4-Br-SBF

\section{1.b. Synthesis of 3-Br-SBF and 3-substituted SBFs}

3-substituted-SBFs have been less developed than their 4substituted isomers described above due to synthetic difficulties. In principle, the general routes described above can also be used to synthesize 3-Br-SBF (incorporation of the bromine atom either on the fluorenone or on the biphenyl). However, as far as we know, only the first approach has been used so far. Thus, 3-bromo-9fluorenone 3-Br-FO appears as a key intermediate in the synthesis of 3-Br-SBF (Scheme 4) and different routes have been reported.

Liao, Jiang and coworkers have used an elegant Pschorr cyclization reaction to form the fluorenone backbone from benzophenone $\mathbf{1 0}$ after a diazotation step ( $55 \%$ yield), Scheme 4 -Top. ${ }^{38,45}$ This reaction is regioselective providing only $\mathbf{3}-\mathbf{B r}-\mathbf{F O}$.

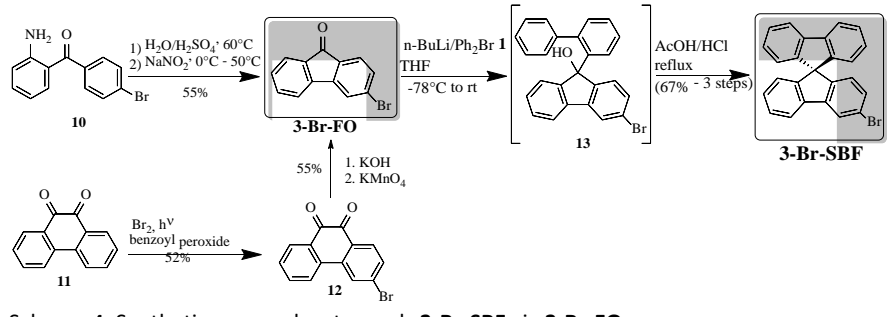

Scheme 4. Synthetic approaches towards 3-Br-SBF via 3-Br-FO

The notion of regioselectivity vs non-regioselectivity is an important point in our discussion and a modern concern in the field of OSCS for organic electronics. ${ }^{1,46,47}$ If in principle, this approach could be used to synthesize the other isomers of bromofluorenone by modifying the position of the bromine atom in the starting material 10 , it will most likely suffer from a selectivity problem in the case of 2-Br-FO and 4-Br-FO. It should be noted that, in theory, 3-Br-FO can also be obtained following a non-regioselective intramolecular cyclization of the biphenyl $\mathbf{2 4}$ (see Scheme 6).

Phenantroquinone $\mathbf{1 1}$ has also been used in the synthesis of $\mathbf{3 - B r}-$ FO following a bromination /oxidation sequence. Thus, $\mathbf{1 1}$ is first brominated to provide $\mathbf{1 2}$ before releasing $\mathbf{3}-\mathbf{B r}-\mathbf{F O}$ by the cleavage of the $\mathrm{C} / \mathrm{C}$ bond linking the two carbonyl groups under the action of $\mathrm{KOH}$ and $\mathrm{KMnO}_{4}$ (29\% over the two steps, Scheme 4, Bottom). ${ }^{48}$ From 3-Br-FO, 3-Br-SBF was then synthesized following the classic sequence of spirofluorene introduction (formation of fluorenol $\mathbf{1 3}$ and cyclization). All the 3-substituted SBFs reported in the literature (except 3-Ph-SBF) were synthesized from 3-Br-SBF platform, Scheme 5. Notably, electron withdrawing (such as phosphine oxide in $\left.3-\mathrm{POPh}_{2}-\mathrm{SBF}\right)^{45}$ and/or electron donating units (such as carbazole oligomers in 3-diNCbz-SBF ${ }^{38}$ ) were introduced providing efficient functional materials as described in Part 4.
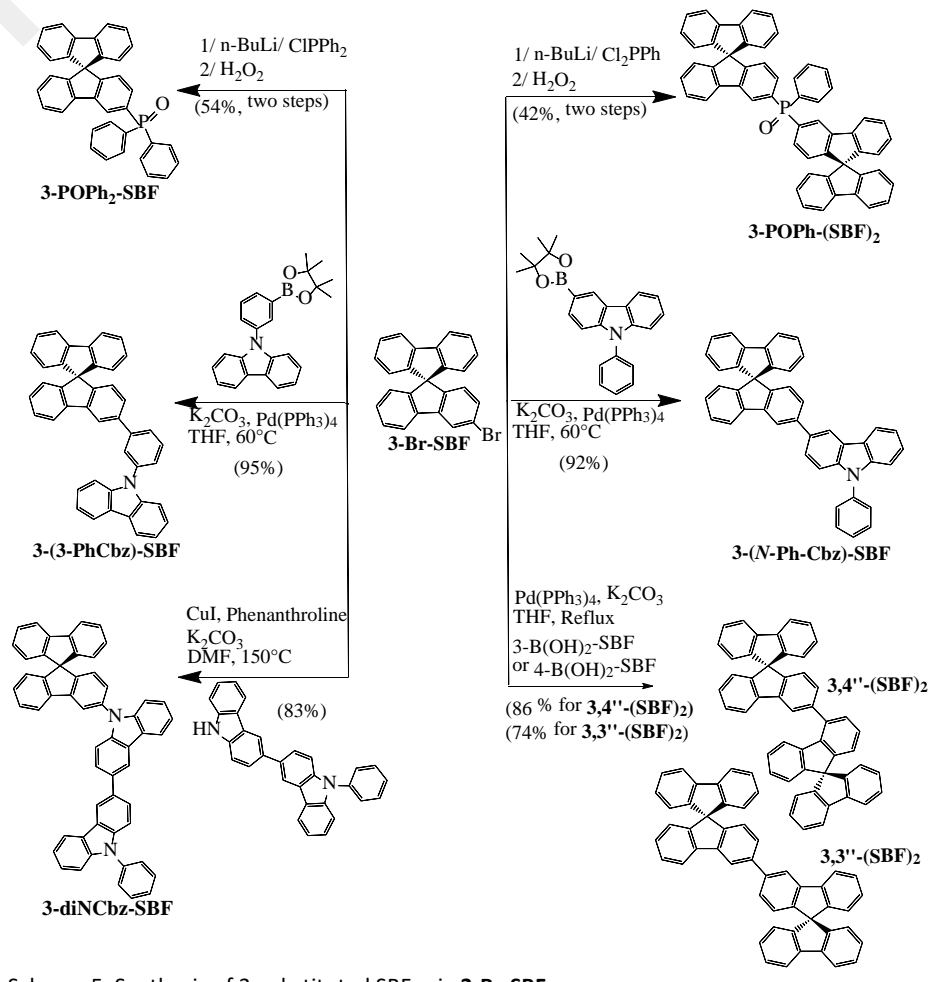

Scheme 5. Synthesis of 3-substituted SBFs via 3-Br-SBF 


\section{1.c. Synthesis of 1-Br-SBF and 1-substituted SBFs}

1-substituted SBFs are far less developed than the two other families described above and represent the youngest generation of SBF positional isomers. To the best of our knowledge, the first example of a 1-substituted SBF (1-Ph-SBF) for organic electronics was synthesized in May 2017 from 1-iodofluorenone 1-I-FO ${ }^{39}$, although some examples had been reported earlier. ${ }^{49}$ As for the two preceding families of positional isomers, 1halogenofluorenones (1-I-FO and 1-Br-FO) are key compounds in the synthesis of 1-substituted SBFs.

Synthetic investigations towards such 1-halogenofluorenones have recently encountered a significant development, which will clearly help building 1-substituted SBFs in the future.

In 1951, 1-aminofluorenone $\mathbf{1 7}$ was reported by Kharash and Bruice from the oxidation of fluoranthene 14 in 1-carboxylic acid

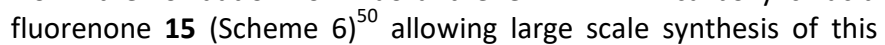
compound (note that an earlier work reported amine $17^{51}$ ). This strategy is appealing as it allows in one step to build the fluorenone core with a substituent, ie a carboxylic acid, located at $\mathrm{C} 1$. The carboxylic acid $\mathbf{1 5}$ is then converted to its amide $\mathbf{1 6}$ and further converted to its amine 17. In 2016, the group of Harper ${ }^{52}$ screened various synthetic pathways towards 1-substituted fluorenones. This group notably revisited the original synthesis of 1-I-FO and delivered many different synthetic pathways towards other 1substituted fluorenones such as 1-Br-FO. For example, a regioselective approach towards $1-\mathbf{B r}-\mathbf{F O}$ was explored. The approach is similar to that presented above for 4-Br-SBF (Scheme 2). However, to reach 1-Br-SBF, the bromine atom must be located at the $\alpha$ position of the carboxylate group on biphenyl $\mathbf{2 1}$ (whereas the bromine atom and ethyl ester group were each located on a different phenyl ring in $\mathbf{6}$, Scheme 2 ). Thus, after a selective iodation of 18 providing 19 and protection of the carboxylic acid as a methyl ester group (20), biphenyl $\mathbf{2 1}$ is involved in an intramolecular cyclization regioselectively providing 1-Br-FO.

In 2016, Bentabed-Ababsa et al reported that the direct iodation at C1 of fluorenone 3 in a 52\% yield was possible when using an in situ deprotolithiation-zincation sequence. ${ }^{53}$ Other side products were nevertheless detected during this reaction.

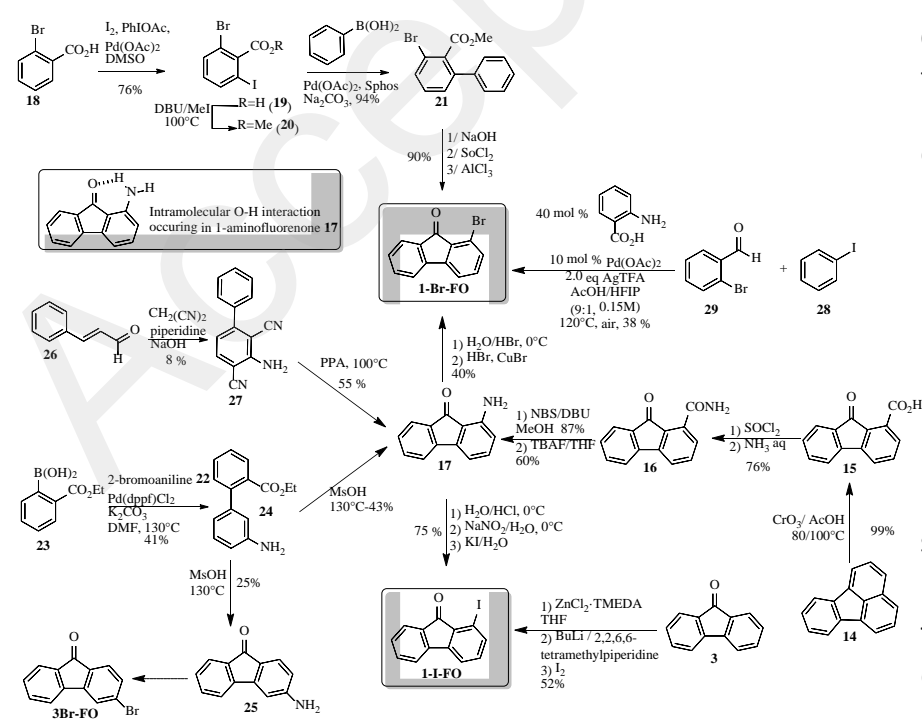

Scheme 6. Synthesis of 1-substituted SBFs 1-Cbz-SBF and 1-Ph-SBF

The approach developed by our group towards 1-I-FO via the 1aminofluorenone $\mathbf{1 7}$ presented the advantage to also lead to another positional isomer, ie $\mathbf{3}$-aminofluorenone $\mathbf{2 5}$, of interest in the purpose of this article. ${ }^{39}$ This route was based on a Pd crosscoupling between 3-bromoaniline 22 and (2(ethoxycarbonyl)phenyl)boronic acid $\mathbf{2 3}$ to give the biphenyl $\mathbf{2 4}$ further cyclized in methanesulfonic acid to provide $\mathbf{1 7}$ and $\mathbf{2 5}$ in 43 and $25 \%$ yield resp.. Thanks to the rotation of the $\mathrm{C} / \mathrm{C}$ bond of the biphenyl linkage in $\mathbf{2 4}$, the cyclization can occur on the two ortho positions of the aminophenyl core. This cyclization step is therefore not regioselective. Fortunately, the authors reported that the separation of the two aminofluorenones $\mathbf{1 7}$ and $\mathbf{2 5}$ on column chromatography was easy due to the different interactions with silica gel. Indeed, in 17, the proximity between the oxygen atom of the ketone and the amino group leads to intramolecular hydrogen bond (Scheme 6, inset), which is not the case with isomer 25. As it is known that the ratio of regioisomers formed in such a type of cyclization can be tuned by varying experimental conditions such as the temperature of the reaction or the solvent, ${ }^{1,46,47}$ this approach provides a promising synthetic route. In other hand, a regioselective strategy towards $\mathbf{1 7}$ was developed by Velasco and $\mathrm{Yu}^{54}$ They have reported that 3-aminobiphenyl-2,4-dicarbonitrile $\mathbf{2 7}$ in polyphosphoric acid can undergo both a cyclization and decyanation step providing 1-aminofluorenone 17 (55\% yield). The substitution of the $\mathbf{1 7}$ by an iodine atom was then classically performed via a Sandmeyer reaction yielding 1-I-FO with 75\% yield.

Finally, the Sorensen's group has reported an elegant and efficient one-pot synthesis of 1-Br-FO via a Pd(II)-catalysed C(sp $\left.{ }^{2}\right)$ functionalization cascade starting from iodobenzene 28 and 2bromo-benzaldehyde 29 and using anthranilic acid as transient directing group ${ }^{55}$ This approach is rapid, efficient ( $38 \%$ yield) and, in our point of view, the best synthetic strategy reported to date.

Thus, in the last three years, several synthetic investigations towards 1-halogenofluorenones were carried out. These studies provide different synthetic routes to these key molecules, which are indeed of great interest to construct functional materials.

Nevertheless, the literature does not yet report any 1-halogeno$\mathrm{SBF}$. Indeed, in the 1-substituted SBFs reported to date, the substituent was introduced on the fluorenone backbone prior to the spirolinked fluorene unit (for example from fluorenone $\mathbf{3 0}$ for 1Cbz-SBF or from fluorenone $\mathbf{3 1}$ for 1-Ph-SBF, Scheme 7). We believe that the successful synthesis of 1-halogeno SBFs will be an important step to increase the diversity of 1-substituted SBF based compounds.

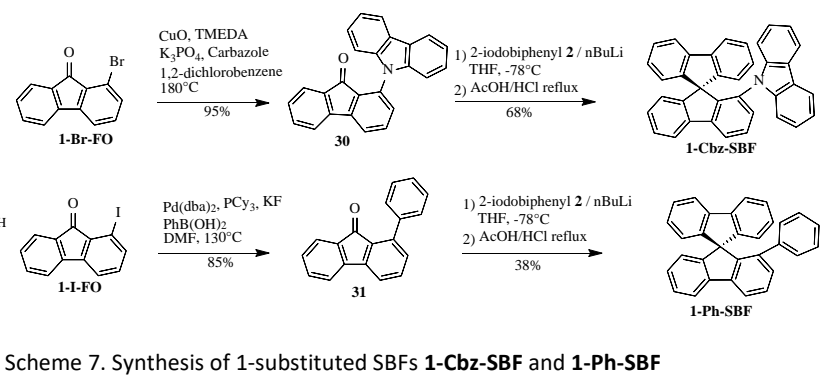

In March 2019, C1-linked SBF dimers were reported (Scheme 8). ${ }^{6}$ These molecules have shown the highest performance reported to date for a Pure HydroCarbon (PHC) material as host in blue 
PhOLEDs (see part 5). This shows the strong potential of the C1-SBF scaffold.

The four C1-linked SBFs, 1,2"'-(SBF) $)_{2}, 1,3^{\prime \prime}-(\mathrm{SBF})_{2}$ and 1,4"-(SBF $)_{2}$ were synthesized following a similar approach starting from their corresponding pinacol derivatives, 2-Bpin-SBF, 3-Bpin-SBF and 4Bpin-SBF (Scheme 8, top). These pinacols were first coupled with 1bromofluorenone 1-Br-FO to provide the corresponding fluorenones 1,2'-FO-SBF, 1,3'-FO-SBF and 1,4'-FO-SBF with high yields (70 to $85 \%$ ) showing that these reactions were weakly dependent of the SBF substitution pattern. Classically, these fluorenones were converted to their corresponding dimers with high yields. Again, the authors noted that despite a strong sterically hindered environment, the spirolinked fluorenes can be efficiently introduced in the last step with the pending SBF already in place. This feature should be advantageously used in the future to construct C1-linked SBF materials. However, due to this steric congestion, 1,1"-(SBF) $)_{2}$ was reported through a different synthetic pathway (Scheme 8, Bottom). 1-Br-FO was first dimerized through a one-pot Pd-catalysed coupling to give the difluorenone dimer 1,1'(FO) $)_{2}$ before forming the bis-diol intermediate $\mathbf{3 2}$ further cyclized in 1,1"-(SBF) ${ }_{2}$ with $\mathrm{HBr} / \mathrm{AcOH}$.

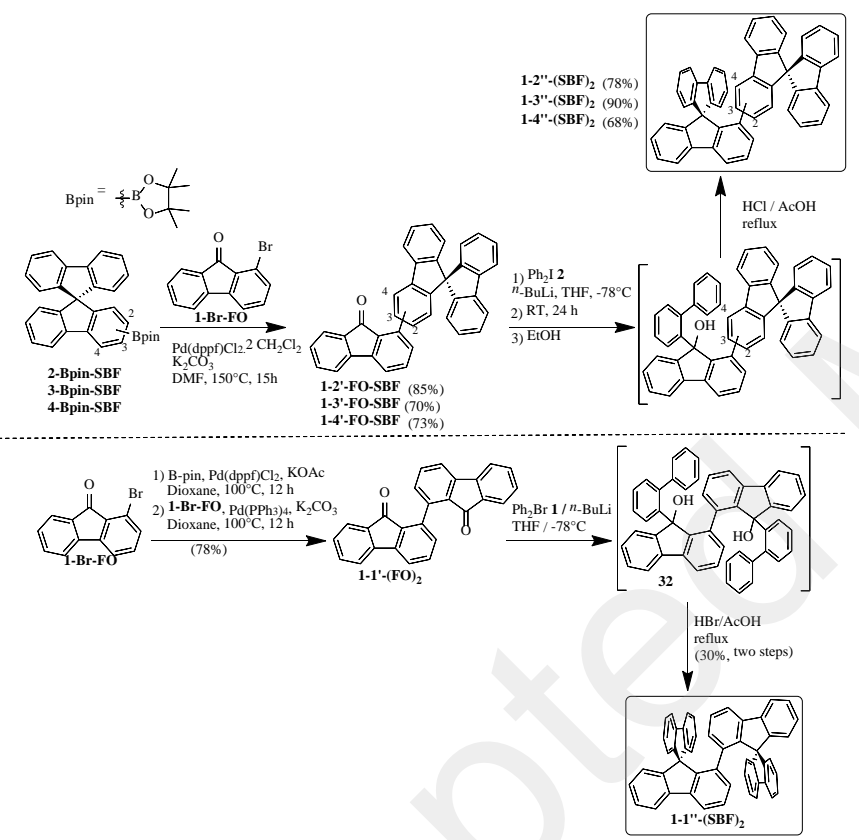

Scheme 8. Synthesis of the C1-linked SBF dimers: $1,2^{\prime \prime}-(\mathrm{SBF})_{2}, 1, \mathbf{3}^{\prime \prime}-(\mathrm{SBF})_{2}$ and $1, \mathbf{4}^{\prime \prime}$ (SBF) ${ }_{2}$ (Top) and 1,1"-(SBF) ${ }_{2}$ (Bottom)

To conclude, efficient synthetic routes have now been developed for all the SBF regioisomers. This was a key point and the first step towards their use in materials science and electronics.

\section{Part 2. Influence of the SBF substitution pattern on the electronic properties: Focus on the origin of the $\pi$-conjugation breaking}

In order to precisely highlight the differences linked to the substitution pattern related to the electronic properties, this second part will focus on the only work described to date that covers the four SBF isomers. These four isomers, 1-Ph-SBF, 2-PhSBF, 3-Ph-SBF and 4-Ph-SBF, are all substituted with a simple phenyl ring (Figure 2- Top). ${ }^{39}$ The original question of this pioneer work was: What is the impact of the substitution on the electronic properties and particularly on the $E_{T}$, key property for PhOLED applications? Two important parameters, driving these properties, will be discussed in detail: the electronic parameter (nature of the linkage and bridge substitution) and the steric parameter (fluorene/fluorene dihedral angle). The electronic properties are gathered in Table 1.

The chief structural parameter driving the electronic properties is the relative position of the pendant substituent (herein the phenyl ring) with respect to the fluorene. ${ }^{34,35}$ Thus, 2-Ph-SBF possesses a fluorene/phenyl dihedral angle of $37.4^{\circ}$, very similar to that of 3Ph-SBF, $34.2^{\circ}$ (values obtained from X-ray, Figure 2-Top). In 3-Ph$\mathrm{SBF}$, the meta linkage between the pendant phenyl ring and its resulting electronic decoupling should strongly reduce the conjugation between the two fragments. We will see later that it is not as simple.

Table 1. Electronic data of 1-Ph-SBF, 2-Ph-SBF, 3-Ph-SBF, 4-Ph-SBF and SBF

\begin{tabular}{|c|c|c|c|c|c|c|}
\hline & 1-Ph-SBF & 2-Ph-SBF & 3-Ph-SBF & 4-Ph-SBF & SBF \\
\hline \multicolumn{2}{|c|}{$\begin{array}{l}\lambda_{\text {abs }}(\varepsilon)^{\mathrm{a}}(\mathrm{nm}) \\
\left(\times 10^{4} \mathrm{~L} \mathrm{~mol}^{-1}\right. \\
\left.\mathrm{cm}^{-1}\right)\end{array}$} & $\begin{array}{c}298 \\
(0.98) \\
309 \\
(1.66)\end{array}$ & $\begin{array}{c}296 \\
(2.44) \\
308 \\
(2.31) \\
319 \\
(1.60)\end{array}$ & $\begin{array}{l}297(0.92) \\
310(1.49) \\
316(0.64)\end{array}$ & $\begin{array}{c}297 \\
(1.07) \\
309 \\
(1.49)\end{array}$ & $\begin{array}{l}297(0.72) \\
308(1.45)\end{array}$ \\
\hline \multicolumn{2}{|c|}{$\lambda_{\mathrm{em}}{ }^{\mathrm{a}}(\mathrm{nm})$} & 313,323 & 334,350 & 332,343 & 359 & 310,323 \\
\hline \multicolumn{2}{|c|}{$\mathrm{QY}^{\mathrm{a}}$} & 0.61 & 0.87 & 0.74 & 0.42 & 0.40 \\
\hline \multicolumn{2}{|c|}{$\tau_{\text {fluo }}(n s)^{a}$} & 5.16 & 1.56 & 5.74 & 4.20 & 4.60 \\
\hline \multicolumn{2}{|c|}{$\mathrm{k}_{\mathrm{r}}\left(\times 10^{8}\right)\left(\mathrm{s}^{-1}\right)$} & 1.22 & 5.60 & 1.29 & 1.00 & 0.87 \\
\hline \multicolumn{2}{|c|}{$\mathrm{k}_{\mathrm{nr}}\left(\times 10^{8}\right)\left(\mathrm{s}^{-1}\right)$} & 0.72 & 0.83 & 0.45 & 1.40 & 1.30 \\
\hline \multicolumn{2}{|c|}{$\mathrm{HOMO}^{\mathrm{b}}(\mathrm{eV})$} & -5.94 & -5.86 & -5.94 & -5.95 & -5.95 \\
\hline \multicolumn{2}{|c|}{$\operatorname{LUMO}^{\mathrm{b}}(\mathrm{eV})$} & -1.73 & -1.99 & -1.77 & -1.87 & -1.74 \\
\hline $\begin{array}{l}\Delta \mathrm{E} \\
(\mathrm{eV})\end{array}$ & $\begin{array}{l}\mathrm{Opt}^{\mathrm{c}} \\
\mathrm{El}^{\mathrm{b}}\end{array}$ & $\begin{array}{l}3.95 \\
4.21 \\
\end{array}$ & $\begin{array}{l}3.70 \\
3.87 \\
\end{array}$ & $\begin{array}{l}3.78 \\
4.17 \\
\end{array}$ & $\begin{array}{l}3.82 \\
4.08 \\
\end{array}$ & $\begin{array}{l}3.97 \\
4.21 \\
\end{array}$ \\
\hline \multicolumn{2}{|c|}{$E_{\mathrm{T}}(\mathrm{eV})^{\mathrm{d}}$} & 2.86 & 2.56 & 2.83 & 2.78 & 2.88 \\
\hline \multicolumn{2}{|c|}{$T_{\text {phospho }}(s)^{d}$} & 5.8 & 3.3 & 5.4 & 4.7 & 5.3 \\
\hline
\end{tabular}

a. in cyclohexane, b. from CVs, c. from UV-Vis spectra, d. in 2-Me-THF at 77K.

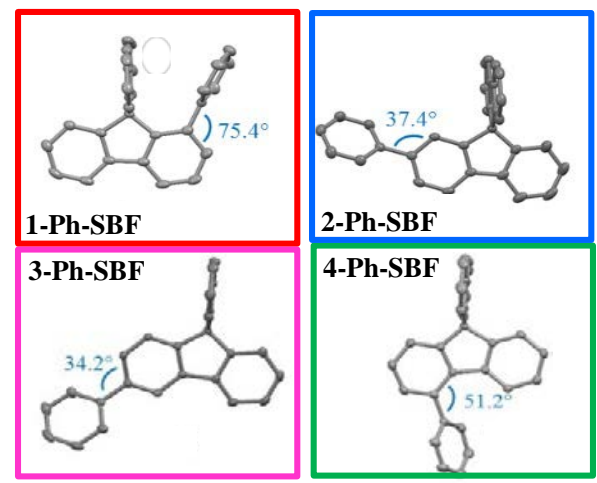



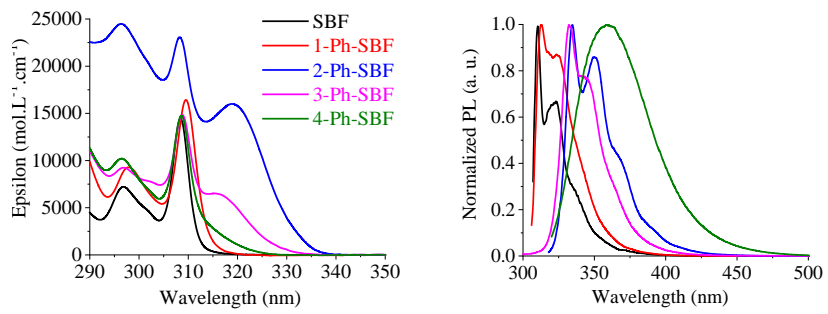

Figure 2. 1-Ph-SBF, 2-Ph-SBF, 3-Ph-SBF and 4-Ph-SBF. Top. ORTEP drawing (ellipsoid probability at $50 \%$ level) from X-Ray crystallography, Bottom. Absorption (Left) and emission (Right) spectra in cyclohexane (SBF is added for comparison purpose)

In 1-Ph-SBF and 4-Ph-SBF, the phenyl/fluorene dihedral angle is impressively larger, $75.4^{\circ}$ and $51.2^{\circ}$ respectively. This is due to a higher steric hindrance between the pendant phenyl ring and either the cofacial fluorene in the case of $\mathbf{1 - P h - S B F}{ }^{39}$ or the hydrogen atoms of the substituted fluorene in the case of 4-Ph-SBF. ${ }^{35}$ Therefore, two molecules possess a small angle (2-Ph-SBF and 3-Ph-SBF) and the two others a large one (1-PhSBF and 4-Ph-SBF). This structural characteristic will be one of the key parameters involved in the different electronic properties described below for all the SBF isomers. Let's first have a look on the consequences on the absorption properties.

First, we need to remind that unsubstituted SBF exhibits two characteristic absorption bands at 297 and $308 \mathrm{~nm}(\pi-\pi *$ transitions). ${ }^{35}$ The four phenyl-substituted SBF isomers all display these two bands (Figure 2-Bottom, left). In addition to these bands, 2-Ph-SBF displays a large one at $319 \mathrm{~nm}$, translating an extension of the conjugation to the pending phenyl unit. This extension of conjugation was assigned to the combination of two parameters: the para linkage (positional effect) and the small dihedral angle (steric effect) adopted between the pending phenyl and the fluorene. Instead of this large band at $319 \mathrm{~nm}$, the spectrum of 4-Ph-SBF presents a weak band tail between 309 and $325 \mathrm{~nm}$ signing a conjugation disruption due to the large angle formed between the fluorene and the phenyl at $\mathrm{C} 4 .^{35}$ In this case, the steric effect is predominant over the electronic effect as an ortho linkage should in principle allow a similar electronic coupling than a para one.

The meta linkage of both 1-Ph-SBF and 3-Ph-SBF has revealed different behaviours. Indeed, the absorption spectrum of 3-PhSBF displays a large band at $316 \mathrm{~nm}$, very similar to that of 2Ph-SBF with nevertheless a molar absorption coefficient 2.5 times lower (Table 1). This extension of the $\pi$-conjugation appeared surprising in the light of the literature as it was commonly admitted that there is a better delocalisation of $\pi$ electrons following the para/ortho/meta sequence. ${ }^{48,56-61}$

As 3-Ph-SBF presents a relatively intense degree of conjugation between the phenyl and the fluorene, its behaviour is different to that of its building block meta terphenyl (in absorption spectroscopy, meta terphenyl displays a maximum at $246 \mathrm{~nm}$ and para terphenyl at $277 \mathrm{~nm}) .^{62}$ The conclusion drawn by the authors was that the 'linkage' effect could not totally explain this feature and other parameters should be invoked. The authors have assigned this particularity to the presence of the spiro bridge.
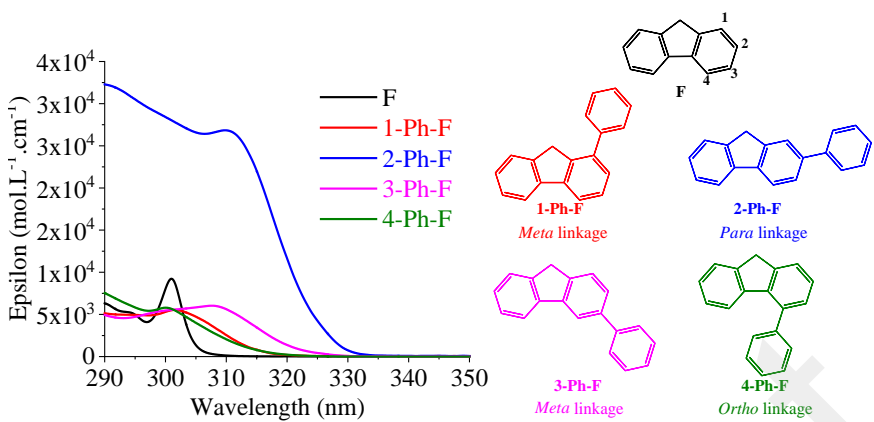

Figure 3. Absorption spectra in cyclohexane (Left) and molecular structures (Right) of 1-Ph-F, 2-Ph-F, 3-Ph-F and 4-Ph-F and F.

By studying model compounds with different bridge substitution (the four isomers of fluorenes 1-Ph-F, 2-Ph-F, 3Ph-F and 4-Ph-F, Figure 3-Right), the authors have shown that this bridge substitution was strongly involved in the extension of the conjugation observed in 3-substituted SBFs. Indeed, both 3-Ph-SBF (Figure 2- Bottom, left) and 3-Ph-F (Figure 3Left) display a large band characteristic of the electronic coupling between fluorene and phenyl but possess interestingly different intensities. It is clear that this bridge effect will deserve to be more investigated in the future in order to control and tune the photophysical properties of the resulting materials.

The other meta-linked SBF, 1-Ph-SBF, displays a complete $\pi$ conjugation breaking (Figure 2-Bottom, left) as its reported UV-vis absorption spectrum is almost identical to that of SBF. This breaking arises from two parameters: the meta linkage (which cannot completely break the conjugation as exposed above for 3-Ph-SBF) and the very large phenyl/fluorene dihedral angle caused by the presence of the cofacial fluorene. This has been confirmed by the absorption spectrum of the corresponding model compound 1-Ph-F, which is very different as it displays a long tail (Figure 3-Left), reflecting a certain degree of conjugation between the pending phenyl and the fluorene moiety. Indeed, the pendant phenyl ring in 1-Ph-F is not sterically hindered oppositely to that of 1-Ph-SBF. Thus, the nature of the linkage (electronic effect) and its position (steric effect) are two key parameters of the $\pi$-electrons delocalization. Nevertheless, the bridge substitution is also an important parameter to consider. For example, despite different linkages, meta isomer 1-Ph-F and ortho isomer 4-Ph-F possess an almost identical absorption spectrum (Figure 3Left), showing that the bridge can cancelled the effect of the linkages on the conjugation length. This is a different behaviour than that highlighted for the couple 1-Ph-SBF/4-PhSBF and reveals the key role played by the bridge.

As for the absorption properties, the fluorescence properties of the four SBF isomers are also very different depending on the substitution pattern and allow to obtain efficient emitters in different ranges of colour (Figure 2-Bottom, right). 4-Ph-SBF even appears as a remarkable example discussed in detail in Part 3. As 2-Ph-SBF and 3-Ph-SBF possess similar emission spectra $\left(\lambda_{\max }=334\right.$ and $332 \mathrm{~nm}$ resp.) and quantum yields in solution ( 0.87 and 0.74 resp.), from a spectral shape point of view, para and meta linkages are almost indistinguishable in fluorescence. As in absorption, the emission spectrum of 1-PhSBF is very similar to that of its building block SBF, showing that the electronic effect of the pendant phenyl ring is also 
almost erased at the excited state. To sum up, for all the isomers, the absorption and emission spectra at room temperature follow the same trend, which is driven by the nature of the linkage (ortho, meta and para) and the steric hindrance induced by these linkages. At 77K, the phosphorescence properties were found to be different as well as the role played by the discussed parameters.

As the main interest of SBF isomers is their capacity to host phosphors in PhOLEDs, their triplet state energies $\left(E_{T}\right)$ are relevant data. When designing host materials for PhOLEDs, it is essential to know how the $E_{\mathrm{T}}$ varies when adding molecular fragments (Figure 4).
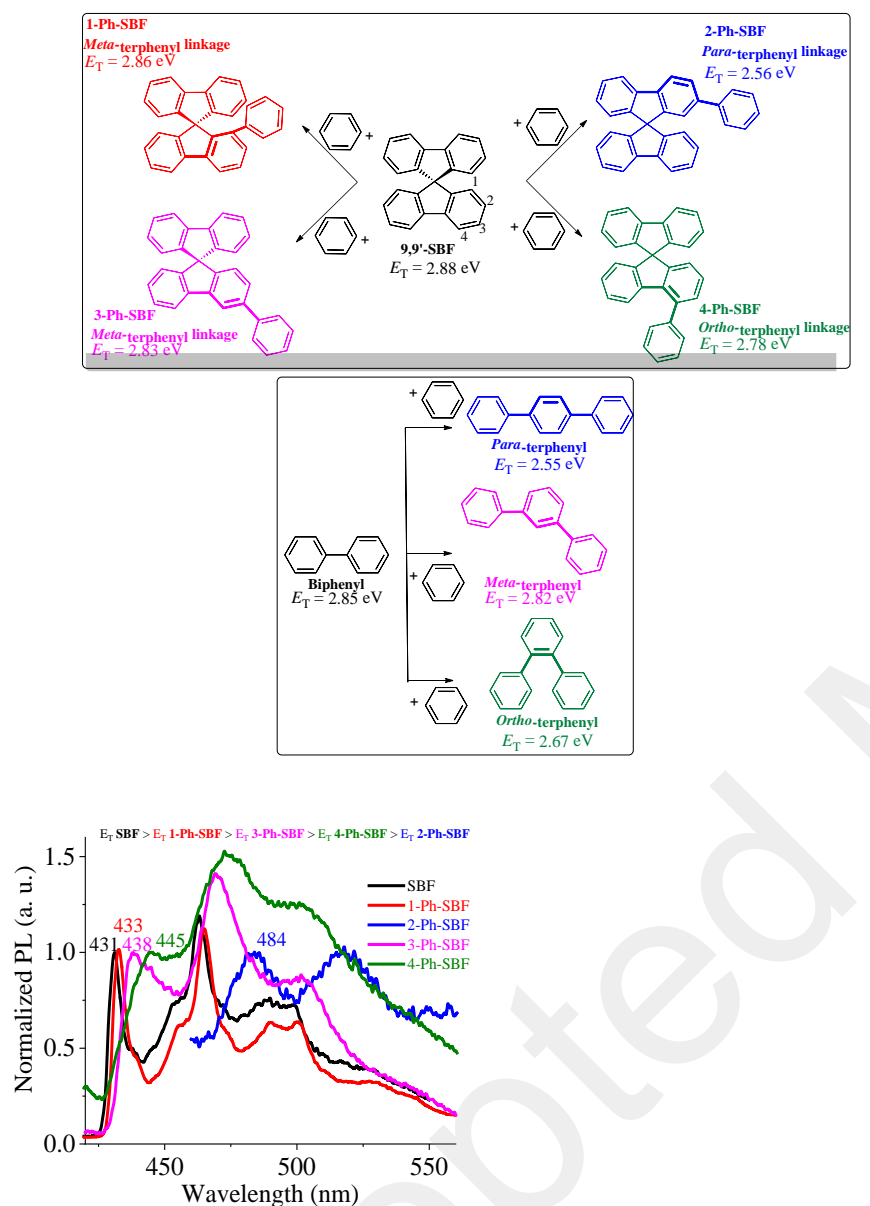

Figure 4. Effect of the phenyl substitution on the $E_{\mathrm{T}}$ of SBF (Top) and biphenyl (Bottom)

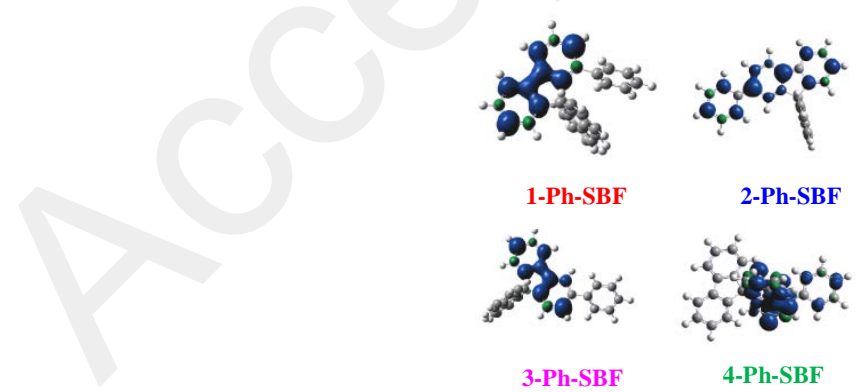

Figure 5. 1-Ph-SBF, 2-Ph-SBF, 3-Ph-SBF and 4-Ph-SBF. Emission spectroscopy at $77 \mathrm{~K}$ in 2-Me-THF (Left) and SDD triplet with isovalues of 0.004 (Right), SBF is added for comparison purpose)
Thanks to the emission spectra at 77K, the $E_{\mathrm{T}}$ of 1-Ph-SBF, 2Ph-SBF, 3-Ph-SBF and 4-Ph-SBF were respectively estimated at ca $2.86,2.56,2.83$ and $2.78 \mathrm{eV}$ (Figure 5-Left). Due to the $\pi$ conjugation disruption, the meta-substituted terphenyl core of 1-Ph-SBF and 3-Ph-SBF leads to a high $E_{\mathrm{T}}$ compared to the para-substituted terphenyl core of 2-Ph-SBF and, to a lesser extent, to the ortho-substituted terphenyl core of 4-Ph-SBF. Thus, the $E_{\mathrm{T}}$ of 1-Ph-SBF (2.86 eV) is almost identical to that of SBF $\left(E_{T}=2.88 \mathrm{eV}\right)$ and there is no electronic influence of the pendant phenyl. Oppositely to the conclusions drawn above for $\mathrm{S}_{1}$, the authors reported that the emission from $\mathrm{T}_{1}$ state follows the classical para/ortho/meta sequence as the $E_{\mathrm{T}}$ increases as follows 2-/4-/3-/1-Ph-SBF. The linkage fully drives the $E_{\mathrm{T}}$ whereas the bridge and the steric hindrance are dominant parameters at room temperature. The same effect is also reported for the fluorene series presented Figure 3, highlighting that this trend is general. ${ }^{39}$ Our group has tried to rationalize this feature. Indeed, thanks to theoretical calculations, we have shown that the triplet exciton of 3-PhSBF and 1-Ph-SBF is exclusively localized along the substituted fluorene, the pendant phenyl having no contribution (Figure 5Right). Both molecules display hence a high and similar $E_{\mathrm{T}}$. In 4-Ph-SBF, as the triplet exciton is partially delocalized on the pendant phenyl, the $E_{\mathrm{T}}$ is decreased. A point noted by the authors is that the delocalization of the triplet exciton is different to that of the HOMO and LUMO (Figure 6) highlighting a different contribution of the pendant phenyl ring. This is discussed below.

Electrochemical studies of these SBF isomers have shown that the contributions of the phenyl ring in the electronic distribution of the HOMO/LUMO are different depending on the substitution pattern (Figure 6). This is discussed below. Despite their different phenyl substitution positions, the HOMO of 1-Ph-SBF, 3-Ph-SBF and 4-Ph-SBF (ca -5.94/-5.95 eV, Table 1) possess the same energy as that of unsubstituted SBF $(-5.95 \mathrm{eV})$ with no or weak electronic density on the pendant phenyl ring (thanks to its para linkage and small dihedral angle, the HOMO of 2-Ph-SBF lies at a higher energy, $-5.86 \mathrm{eV}$ ). The trend is different for the LUMO energy levels. If the phenyl ring at $\mathrm{C} 1$ does not influence the LUMO energy of 1-Ph-SBF $(-1.73$ $\mathrm{eV}$, almost identical to that of SBF, $-1.74 \mathrm{eV}$ ), it has a nonnegligible influence when located at $\mathrm{C} 3$ or at C4 with deeper LUMO reported $(-1.77 \mathrm{eV}$ and $-1.87 \mathrm{eV}$ resp). This is particularly pronounced for 4-Ph-SBF, which presents a significant contribution of the phenyl ring in the LUMO distribution, contrary to its HOMO level (Figure 6-Top). Thus, the phenyl ring has a different influence on the benzenoidal HOMO/quinoidal LUMO distribution depending on the regioisomer involved. We believe that the torsion between the $\mathrm{SBF}$ and the phenyl ring is responsible of the different trend between HOMO and LUMO energy levels. Another series of C1-linked SBF materials have later confirmed this feature (see part 5). ${ }^{6}$
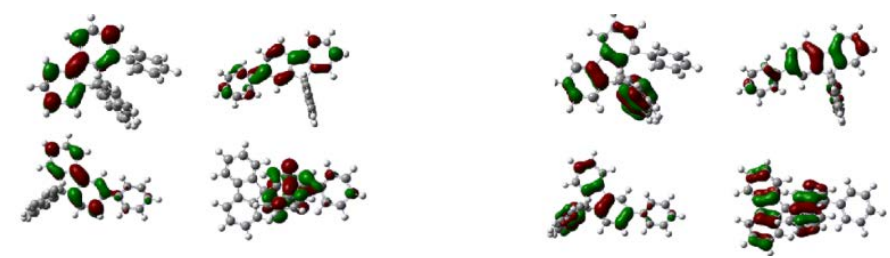

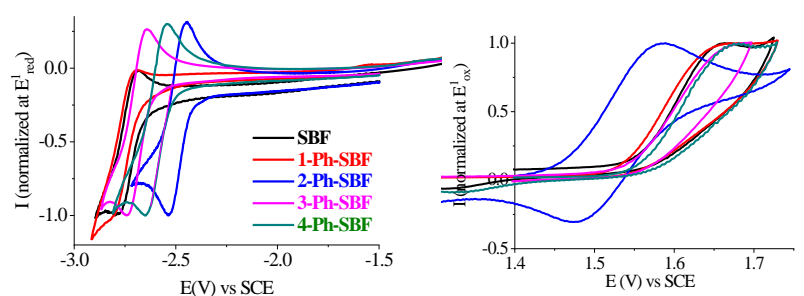

Figure 6. 1-Ph-SBF, 2-Ph-SBF, 3-Ph-SBF and 4-Ph-SBF. Top. LUMO (Left) and HOMO (Right); Bottom.CV in $\mathrm{DMF} / \mathrm{Bu}_{4} \mathrm{NPF}_{6} 0.1 \mathrm{M}$ (reduction, left) and in dichloromethane/Bu $\mathrm{NPF}_{6} 0.2 \mathrm{M}$ (oxidation, right), $100 \mathrm{mV} / \mathrm{s}$ (SBF is provided for comparison purpose).
This structure-property relationship study of the four phenylsubstituted SBFs describes well the general behaviour of all the other SBF regioisomers reported to date in the literature. Some examples of these families are described below. This study also shows the key role played by the bridge, the nature of the linkage and the fluorene/substituent angle on the electronic properties of SBF positional isomers. Such a study lays the foundation of SBF regioisomerism and provides interesting information for further materials design.

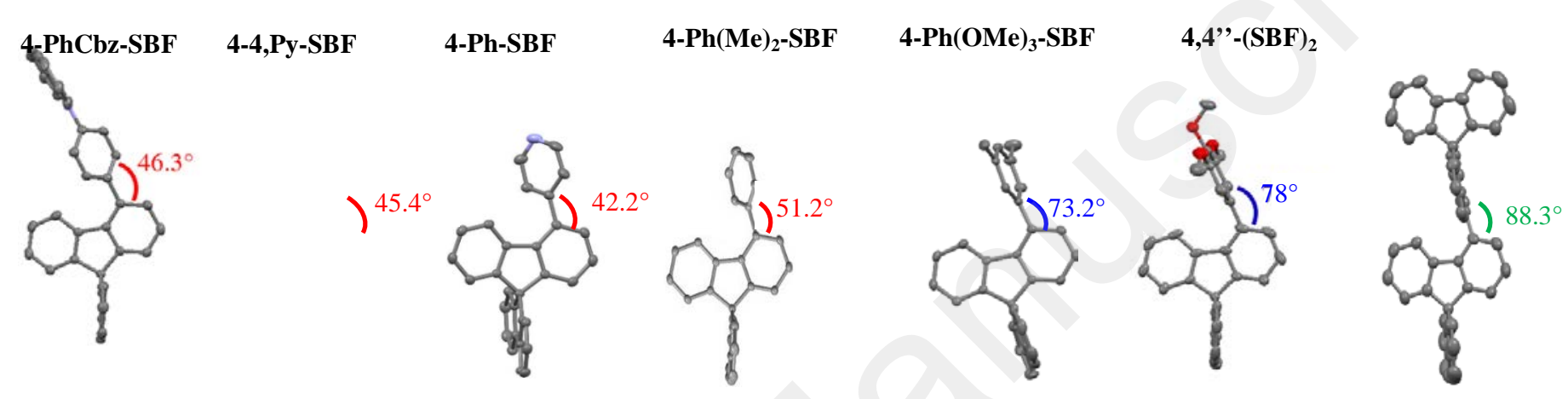

Figure 8. Molecular structures of 4-PhCbz-SBF, 4-4Py-SBF, 4-Ph-SBF, 4-Ph( $\mathbf{M e}_{2}$ )-SBF, 4-Ph(OMe $)_{3}-\mathrm{SBF}$ and 4,4"'-(SBF) ${ }_{2}$ obtained by X-Ray diffraction on single crystals (Front view). The substituent attached on the SBF core is (from left to right): 4-phenylcarbazole; 4-pyridine; phenyl; 3,5-dimethylphenyl; 3,4,5-trimethoxyphenyl and 4-spirobifluorene

\section{Part 3. 4-substituted Spirobifluorenes}

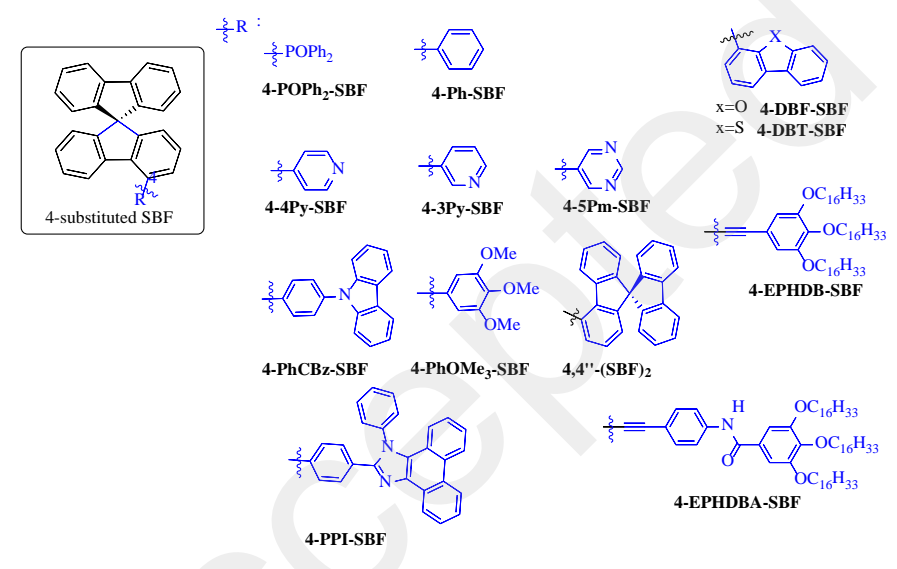

Figure 7. Selected examples of 4-substituted SBFs.

4-substituted SBFs are the $2^{\text {nd }}$ generation of substituted SBF regioisomers, far less developed than their 2-substituted counterparts. Selected examples of 4-substituted SBFs are reported in Figure 7. It should be noted that an exhaustive review on 4-substituted SBFs was published by our group in 2017. ${ }^{3}$ The substitution at C4 of the SBF core was first described in 2009 by the group of Ma with a C4-linked SBF dimer, 4,4"-(SBF) 2 (Figure 7). ${ }^{31}$ Our group has since intensively studied the impact of this substitution on the electronic properties of the SBF core. ${ }^{32,34,35,63,64}$ The common feature between all these molecules is their high $E_{\mathrm{T}}$, which has allowed their use as efficient host materials for green and blue PhOLEDs. ${ }^{3}$ From a more fundamental point of view, many interesting structural and electronic features have been highlighted over the years for this family of molecules. At the beginning of these studies, in 2009, the main questions to answer was: What are the consequences of the C4 substitution on the structural and electronic properties of the SBF core and are these semi-conductors suitable for designing PhOLED hosts? Ten years of research later, we present herein some answers.

As above-mentioned and exemplified in Part 2 with the molecule 4-Ph-SBF, the $\pi$-conjugation breaking observed in 4substituted SBFs is induced by the large dihedral angle between the fluorene and its pendant substituent. This allows to strongly disrupt the $\pi$-electron distribution, providing notably a high $E_{\mathrm{T}}$.

Despite more and more investigation in the last five years, the number of 4-substituted SBFs reported to date is rather limited. ${ }^{3}$ At C4 of the SBF core have been introduced (i) electron withdrawing fragments such as heterocycles (pyridine, 4-4Py-SBF/4-3Py-SBF, ${ }^{32}$ pyrimidine, 4-5Pm-SBF ${ }^{34}$ ) or phosphine oxide unit (4-POPh ${ }_{2}$-SBF), ${ }^{65}$ or (ii) electron donating fragments such as phenylcarbazole (4-PhCBz-SBF), trimethoxyphenyl (4-Ph(OMe) $\left.{ }_{3}-\mathrm{SBF}\right)^{66}$ dibenzothiophene (4DBT-SBF) ${ }^{67}$ or dibenzofuran (4-DBF-SBF), Figure $7 .^{68}$ As a function of the steric congestion induced by the substituent, the dihedral angle between the fluorene and the substituent can be drastically modified, which in turn alters the resulting 
electronic properties. Six selected examples of X-Ray structures are presented in Figure 8. For an unsubstituted phenyl ring (in 4-Ph-SBF) or a phenyl ring analogue such as pyridine (in 4-4Py-SBF), the dihedral angle remains low, around $40 / 50^{\circ}$. If a substituent is attached in para position of the phenyl ring such as in 4-PhCbz-SBF, the dihedral angle remains in the same range. This clearly indicates that the substitution in para position does not add any significant steric hindrance. However, if a substituent is added in meta position of the phenyl ring, the dihedral angle is impressively increased $\left(78^{\circ} \text { in 4-Ph(OMe) }\right)_{3}-\mathrm{SBF}$ and $73.2^{\circ}$ in $\left.4-\mathrm{Ph}\left(\mathrm{Me}_{2}\right)-\mathrm{SBF}\right)$. This angle becomes closer to $90^{\circ}$ when the phenyl attached at C4 is

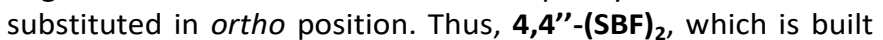
on two C4-linked SBF fragments each substituted at C4 displays an angle as high as $88.3^{\circ}$ (Figure 8-Right). ${ }^{31}$ Therefore, the size and the substitution pattern of the substituent attached at $\mathrm{C} 4$ both have a strong impact on the dihedral angle, which drives the electronic properties (see below).

Thanks to this large fluorene/substituent dihedral angle, there is a strong $\pi$-conjugation disruption in all the 4-substituted SBFs reported in the literature. ${ }^{3}$ In the absorption spectra of these molecules, the intensity of the tail at around $320 \mathrm{~nm}$ characterizes the different degree of electronic delocalization between the fluorene and its substituent (Figure 9- Top, left). Thus, depending of the substituent borne by the fluorene (pyrimidine, pyridine, trimethoxyphenyl etc), the intensity of this tail is different and function of the angle formed between the substituent and the fluorene. This $\pi$-conjugation disruption has a direct influence on the $E_{\mathrm{T}}$ values, which are for all these molecules (i) above $2.7 \mathrm{eV}$ and (ii) higher than their 2substituted counterparts (Figure 9-Bottom, left). However, the influence of the substituent is different for each molecule leading to different $E_{\mathrm{T}}$ values. The highest $E_{\mathrm{T}}$ is reported for the molecules possessing the largest dihedral angle in the series. 4-Ph(OMe) $)_{3}$-SBF and 4,4"-(SBF $)_{2}$ possess indeed a very high $E_{\mathrm{T}}$ of $2.84 \mathrm{eV}$ and $2.81 \mathrm{eV}$, close to that of unsubstituted SBF $(2.88 \mathrm{eV})$, and respectively display the largest dihedral angle of $78.5^{\circ}$ and $88.3^{\circ}$ (Figure 8). ${ }^{34,} 35$ Thus, controlling the fluorene/C4 substituent dihedral angle can be an interesting strategy to control the intensity of the electronic coupling in 4substituted SBFs.
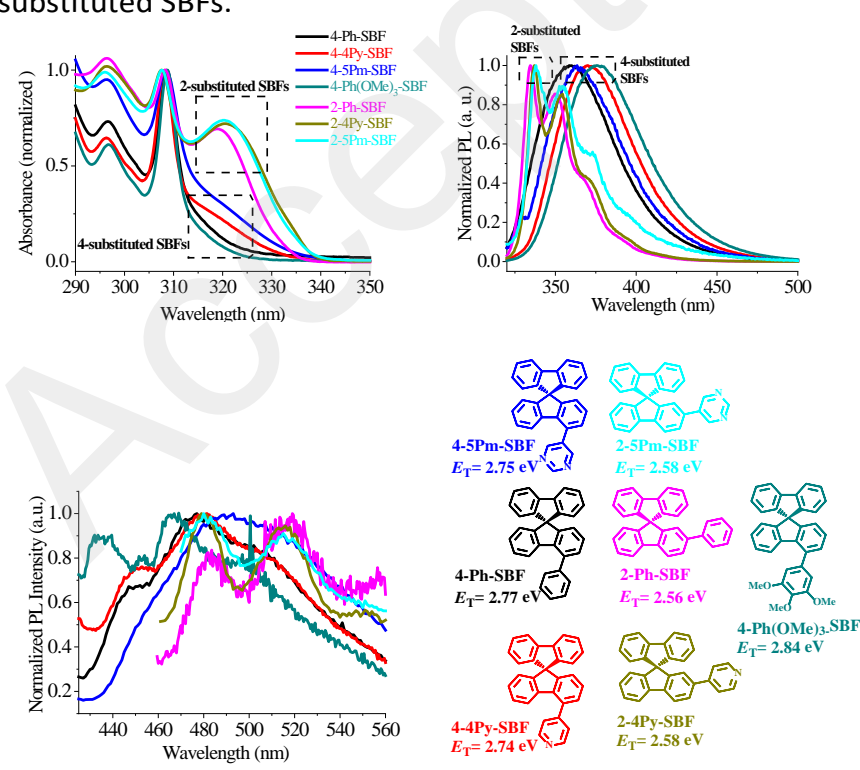

Figure 9. Top. UV-vis absorption (normalized at $309 \mathrm{~nm}$, left) and emission spectra at room temperature (normalized at $\lambda_{\max }$, right) in cyclohexane, of selected examples of 2and 4-substituted SBFs. Bottom. Emission spectra at 77K in 2-Me-THF (Left) and molecular structures of reported compounds (Right).

The most intriguing particularity of 4-substituted SBFs is their uncommon fluorescence. At room temperature, almost all the 4-substituted SBFs reported exhibit similar fluorescence spectra. These spectra are large, structureless (350/380 nm) and strongly red-shifted compared to the other positional isomers substituted at C1, C3 and especially at C2, which display resolved emission bands (Figure 9-Top, right). It is indeed known for $\mathrm{C} 2$-isomers that the $\mathrm{C}$ - $\mathrm{C}$ bond linking the pendant substituent and the fluorenyl core displays a doublebond character in the excited state, rigidifying the structure and leading to a resolved spectrum. ${ }^{69,70}$ Thus, 4-substituted SBFs display a fluorescence emission in a different range than that of the other positional isomers. Why do these isomers possess such very different emission spectra? Despite no complete answer having been provided yet, ${ }^{32,34,35,64}$ some findings recently reported by our group are presented below as a representative example with the couple 4-PhCbz-SBF/4$\mathrm{Ph}(\mathrm{OMe})_{3}-\mathrm{SBF}^{33}$ The fluorescence spectrum of $4-\mathrm{Ph}(\mathrm{OMe})_{3-}$

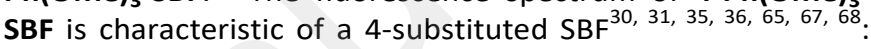
structureless, large and presenting a significant Stokes shift. Thanks to theoretical calculations, the origin of this large Stokes shift and unusual large fluorescence has been explained by the significant difference between the geometries of the ground $\left(\mathrm{S}_{0}\right)$ and first singlet excited $\left(\mathrm{S}_{1}\right)$ states of 4-Ph(OMe) ${ }_{3}-$ SBF (Figure 10-Right). Thus, due to the particular molecular arrangement of the 4-substituted SBF scaffold, in which the pendant substituent is sterically hindered by the hydrogen atoms of the substituted fluorene, ${ }^{35}$ the observed emission results from a large distribution of conformers. On the contrary, 4-PhCbz-SBF presents a well resolved emission spectrum and a small Stokes Shift (Figure 10-Left). As can be seen in Figure 10-Right, the geometries of $S_{0}$ and $S_{1}$ are indeed very similar translating very weak molecular rearrangements between the two states. This behaviour is most likely induced by the bulkiness of the phenylcarbazole unit attached at $\mathrm{C} 4$.

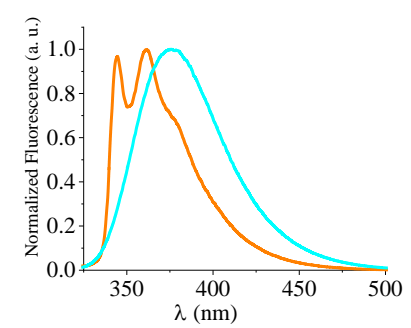

Figure 10. Left. Normalized emission spectra (cyclohexane) of 4-PhCbz-SBF ( $\lambda_{\text {exc }}=295 \mathrm{~nm}$, orange) and 4-Ph(OMe) ${ }_{3}-\mathrm{SBF}$ (blue, $\lambda_{\text {exc }}=309 \mathrm{~nm}$ ), Right. Superimposition of the $S_{0}$ (ground state) and $S_{1}$ (first singlet excited state) molecular structures obtained by molecular modelling of 4-Ph(OMe $)_{3}-\mathrm{SBF}\left(\mathrm{S}_{0}\right.$ : sky blue, $\mathrm{S}_{1}$ : green) and 4-PhCbz-SBF ( $\mathrm{S}_{0}$ : pink, $\mathrm{S}_{1}$ : orange).

In 2009, at the very beginning of the investigation on 4substituted SBFs, there was one important question to address: What is the effect of the SBF substitution pattern on the HOMO/LUMO energy levels? Indeed, the introduction of electron-donating or electron-withdrawing functional groups to adjust the HOMO/LUMO energy levels of a molecule is a 
widely used strategy in the field of organic electronics. However, the goal was to find out about the magnitude of the HOMO/LUMO tuning and notably the difference compared to the first generation of 2-substituted SBFs. This is an important step forward in the design of functional materials. Thus, the literature shows that the introduction of electron-donating or electron-withdrawing groups at $\mathrm{C} 4$ allows to tune the HOMO and LUMO to a lesser extent than at C2. Due to the partial $\pi$-conjugation disruption at $\mathrm{C} 4$ of $\mathrm{SBF}$, the reported electrochemical data indicate that 4-5Pm-SBF ${ }^{34}$ and 4-4Py-SBF display a higher LUMO energy level than their corresponding 2-substituted isomers 2-4Py-SBF and 2-5Pm-SBF. ${ }^{34}$ The SBF core is therefore less influenced by the electronic effects at $\mathrm{C} 4$ than at C2. Nevertheless, the electronic properties of 4substituted SBFs can be drastically changed as a function of (i) the dihedral angle between the substituent and the fluorene and (ii) the nature of this substituent itself (length of its $\pi$ conjugated system / bulkiness etc). ${ }^{71}$ This characteristic should be considered when designing functional materials based on the 4-substituted SBF scaffold.

As mentioned in the introduction, the new generations of SBFs have been designed for organic electronics and especially to host blue and green phosphors in PhOLEDs. Their high $E_{\mathrm{T}}$ and very good thermal/morphological stabilities are key properties which have allowed 4-substituted SBFs to reach in some cases good performance when incorporated in devices (Table 3$).^{3}$ For example, we can cite 4-Ph(OMe) ${ }_{3}-\mathrm{SBF}^{33}$ for which the EQE are reported at ca $10 \%$ in blue PhOLEDs and at ca $20 \%$ in green PhOLEDs, 4-PPI-SBF for which the EQE is reported at ca $17 \%$ in green PhOLEDs. ${ }^{72}$ and 4-DBF-SBF ${ }^{67}$ for which the EQE is recorded at ca $11 \%$ in blue PhOLEDs. Incorporation of an electron accepting phosphine oxide at $\mathrm{C4}\left(\mathbf{4}-\mathbf{P O P h}_{\mathbf{2}}-\mathbf{S B F}\right)$ has led to even higher performance, displaying an EQE of $17.2 \%$ in blue PhOLEDs. ${ }^{65}$ This molecule has even been incorporated in single-layer PhOLEDs, with $\operatorname{Ir}(\mathrm{ppy})_{3}$ as the emitter, leading to an EQE of ca $13 \% .^{63}$ Some of these molecules have also been tested as hosts in white PhOLED such as 4-DBT-SBF, which displays an interesting EQE of $16.9 \% .{ }^{67}$ However, the next generations of $\mathrm{C} 1$ and $\mathrm{C} 3$-linked SBFs have in fact outperformed C4-linked SBFs in hosting phosphors in PhOLEDs (see below).

Other applications for 4-substituted SBFs have also started to emerge in the literature. We can cite for example the luminescent liquid crystalline phases generated from 4EPHDBA-SBF and 4-EPHDB-SBF (Figure 7) ${ }^{64}$ or the association of the 4-SBF scaffold with a diketopyrrolopyrrole fragment to construct electron donors for solar cells. ${ }^{73}$

\section{Part 4. 3-substituted Spirobifluorenes}
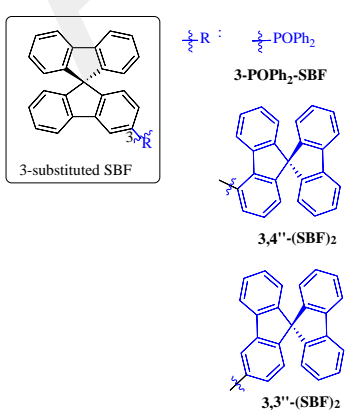

10 | J. Name., 2012, 00, 1-3

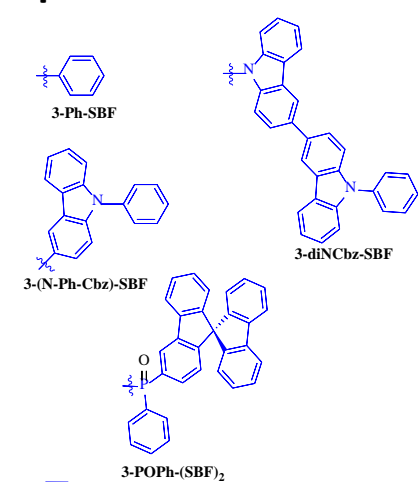

Figure 11. 3-substituted SBFs reported to date.

In the $3^{\text {rd }}$ generation of SBF positional isomers, the $\pi$-conjugation disruption is not directly linked to steric effects but arises from electronic effects induced by the meta linkage. The first 3-substituted SBFs have been reported in 2013 by the group of Liao and Jiang. ${ }^{45}$ In order to reach high-performance PhOLEDs, this group has particularly developed 3-substituted SBFs incorporating functional groups such as phosphine oxide (3-POPh ${ }_{2}$-SBF and 3-POPh-(SBF) $\left.)_{2}\right){ }^{45}$ triazine (3-PhTriazCbzSBF), ${ }^{74}$ or carbazole oligomers (3-(3-PhCbz)-SBF, 3-(N-Ph-Cbz)SBF and 3-diNCbz-SBF). ${ }^{38,75}$ However, until now, less than 10 examples have been reported in the literature making the molecular diversity of 3-substituted SBFs rather poor (Figure 11). In the light of the PhOLEDs performance using 3substituted SBFs as host, among the highest reported to date for all the colours (see below), it is clear that this family will be much more developed in the coming years.

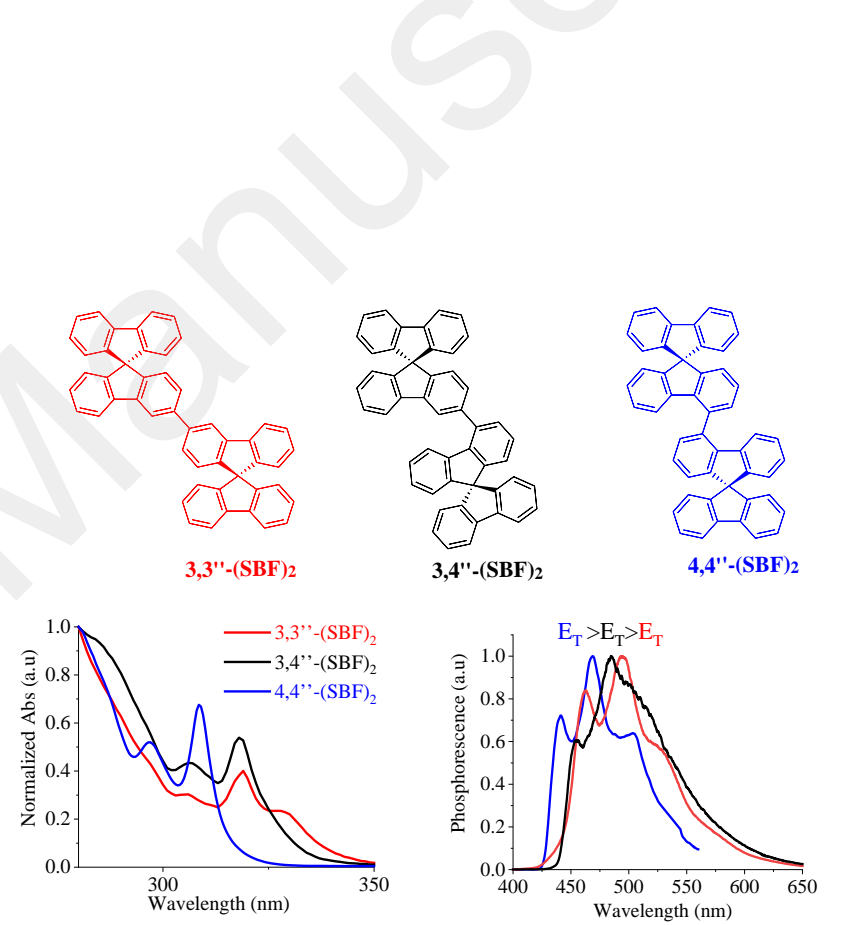

Figure 12. 3,3"'-(SBF) $)_{2}, 3,4$ "'-(SBF $)_{2}$ and 4,4"-(SBF $)_{2}$. Top. Molecular structures. Bottom. UV-vis absorption spectra (Left). Emission spectra at $77 \mathrm{~K}$ (Right)

As exposed in Part 2 for the phenyl isomers 3-Ph-SBF and 4-Ph$\mathrm{SBF}$, the conjugation between the phenyl and the fluorene is more intense in the former than in the latter showing that the steric effect is dominant over the electronic effect to disrupt the conjugation. Is this true for all the 3-substituted SBFs reported in literature? It would seem so. Indeed, the SBF dimers $3,3^{\prime \prime}$-(SBF $)_{2}, 3,4^{\prime \prime}-(\mathrm{SBF})_{2}{ }^{36}$ and $4,4^{\prime \prime}-(\mathrm{SBF})_{2}{ }^{31}$ reported by Jiang and Liao's group (Figure 12-Top) ${ }^{36}$ only differ by the substitution pattern of the two SBF cores (meta-meta, metaortho, and ortho-ortho linkage respectively) and offer herein relevant model compounds. The absorption spectrum of $\mathbf{3 , 3}$ "$(\mathrm{SBF})_{2}$ displays its highest absorption band at $328 \mathrm{~nm}$, this band being absent for $3,44^{\prime \prime}-(\mathrm{SBF})_{2}$ and $4,4{ }^{\prime \prime}-(\mathrm{SBF})_{2},{ }^{31}$ Figure 22 Bottom, left). Thus, the electronic coupling between the two SBF backbones seems to be more efficient in $\mathbf{3 , 3 "}$ "-(SBF $)_{2}$ than

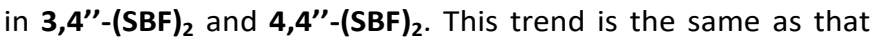
exposed in part 2 for phenyl-substituted SBFs and can 
consequently be correlated to the fluorene/fluorene dihedral angle which decreases from $88^{\circ}$ for $4,4^{\prime \prime}$-(SBF $)_{2}$ to $62^{\circ}$ for $3,4^{\prime \prime}$ $(\mathrm{SBF})_{2}$ and to $38^{\circ}$ for $\mathbf{3 , 3 ^ { \prime \prime } \text { -(SBF) }} \mathbf{2}$ (note that these values have been obtained from X-Ray for 4,4"-(SBF) ${ }_{2}$ and from molecular

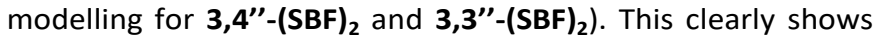
that the steric effect is dominant over the electronic effect and therefore drives the absorption properties. The same trend is observed for the $E_{\mathrm{T}}: \mathbf{3 , 3}$ '"-(SBF) $2(2.68 \mathrm{eV})<\mathbf{3 , 4}$ "'-(SBF) 2 (2.76

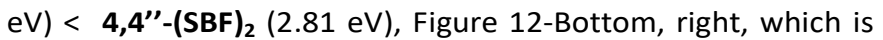
this time different than that reported for 3-Ph-SBF and 4-PhSBF ( $E_{\mathrm{T}}$ of 3-Ph-SBF is higher than that of 4-Ph-SBF, Part 2). At this stage, these two trends remain difficult to rationalize and deserve to be carefully investigated in the future. Thus, in the SBF family, the meta linkage allows a $\pi$-conjugation extension, which is different compared to other $\pi$-systems such as terphenyls. $^{58,62}$ In the light of the literature, the same conclusions regarding the $\pi$-conjugation disruption can be drawn for most of the other 3-substituted SBFs reported to date such as 3-Ph-TriaZCbz-SBF ${ }^{74}$ or 3-diNCbz-SBF. ${ }^{38}$ The conjugation is disrupted but not completely broken. Thus, 3diNCbz-SBF and its 2-substituted derivative possess a similar energy gap (the electronic coupling is nevertheless more intense for the latter) but a different $E_{\mathrm{T}}$ value, the former being higher than the latter $\left(E_{\mathrm{T}}=2.82 \mathrm{eV}\right.$ and $2.72 \mathrm{eV}$ respectively). ${ }^{38}$ In this example, one can hence again conclude that the $E_{\mathrm{T}}$ is driven by the linkage (meta vs para).

From the examples of 3-substituted SBFs reported to date, one can conclude that an electronic coupling between the fluorene and the attached substituent exists, although weak. This is an important feature for the future design of SBF based materials and more fundamentally when thinking about the impact of a meta linkage on the electronic properties.

As only a few comparative studies have been reported, it is difficult to draw a general trend on the impact of a substituent on the HOMO and LUMO energy levels. However, as 3-diNCbzSBF displays a slightly lower HOMO energy level than its 2substituted isomer $(-5.63 \mathrm{eV}$ vs $-5.57 \mathrm{eV})$, it seems that, as observed for the 4-substituted SBFs above exposed, the impact of the substituent on the HOMO/LUMO energy levels is weaker for a 3-substituted SBF than for a 2-substituted SBF. ${ }^{38}$ Similarly, the LUMO energy level of 3-POPh ${ }_{2}-\mathbf{S B F}(-2.56 \mathrm{eV})$ is higher than that of its 2 substituted analogue 2-POPh $\mathbf{2}_{\mathbf{2}}$-SBF ($2.65 \mathrm{eV}) .{ }^{45}$ However, only few data exists today and it appears premature to draw a precise structure-properties relationship map. This point will deserve to be carefully investigated in the future.

To conclude, it is important to mention that very high performance, for green and blue PhOLEDs, was reached with 3-substituted SBFs as hosts, making this family of organic semiconductors very appealing. The first examples of incorporation in a PhOLED of a C3-linked SBF, 3-POPh ${ }_{2}$-SBF and 3-POPh$(\mathrm{SBF})_{2},{ }^{45}$ had shown the potential of this platform. Indeed, when hosting FIr6 in a PhOLED, EQE of $13.6 \%$ and $10.2 \%$ were respectively obtained for 3-POPh $\mathbf{2}_{2}$-SBF and 3-POPh-(SBF $\left.)_{2}\right)^{45}$ These EQE values were relatively high and promising for a first example. This work revealed that the C3 position of SBF could solve the problem of low triplet energy using the traditional C2 position and has opened new paths in the field of high $E_{\mathrm{T}}$ host materials. Used as a host in blue PhOLEDs or in green TADF OLEDs, $\mathbf{3 , 4 "}$-(SBF) 2 has displayed very high performance (EQE of ca $22 \%$ for both). This value, which has now been exceeded by C1-linked SBF dimers (see part 5), was the highest reported for a blue PhOLED using a PHC material in 2015, showing not only the efficiency of this platform but also its versatility. Similarly, 3-(3-PhCbz)-SBF, 3-(N-Ph-Cbz) SBF ${ }^{75}$ and 3-diNCbz$\mathrm{SBF}^{38}$ have also displayed high EQEs of ca $18 / 19 \%$ in blue PhOLEDs. White PhOLEDs have also been constructed with these molecules as hosts with EQE exceeding $25 \%$ in the case of 3,4"-(SBF) ${ }_{2}$ and $40 \%$ in the case of 3-diNCbz-SBF.

Thus, the 3-substituted SBF scaffold has appeared in the last years as a very promising building unit to construct high efficiency host materials for PhOLEDs and TADF OLEDs. Compared to the C4-linked SBFs, the electronic properties of C3-linked SBFs can be more easily controlled and their performance in electronic devices are higher. The latest generation of C1-linked SBFs described below is even better.

\section{Part 5. 1-substituted Spirobifluorenes}

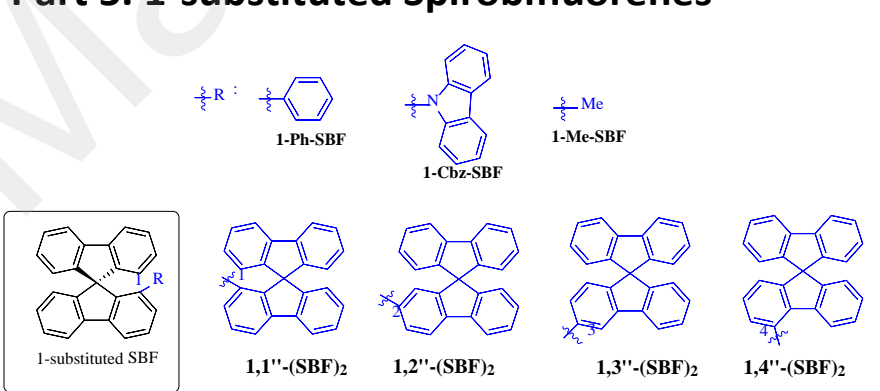

Figure 13. 1-substituted SBFs reported to date

1-substituted SBFs are the latest generation of SBFs. To the best of our knowledge, only six examples of 1-aryl-substituted SBFs for organic electronics have been reported (Figure 13). ${ }^{6,76}$ It must be noted that a SBF possessing at C1 a methyl group (1Me-SBF) has also been reported but as a model compound to study exciton splitting. ${ }^{77}$

The aryl substitution at C1 combines the two previously described advantages of the substitution at C3 (meta linkage) and at C4 (strong steric hindrance). This combination has appeared to be the most efficient to break the $\pi$-conjugation and hence keep a very high $E_{\mathrm{T}}$ (see part 2). This breaking has been mainly assigned to the high dihedral angle formed between the substituent and the fluorene (the electronic decoupling linked to the meta linkage does not lead to a complete $\pi$-conjugation breaking) and is therefore caused by a steric parameter. This particularity has been advantageously used to design high $E_{\mathrm{T}}$ host materials for PhOLEDs (see below with the C1-linked SBF dimers). The singular geometry of the 1-substituted SBF scaffold also leads to another appealing characteristic, which should be used in the future years: the cofacial arrangement between the substituent and the facing 
fluorene. Indeed, when a substituent is linked at C1 of a SBF core, preliminary studies have shown ${ }^{76}$ that there are through space interactions between this substituent and its facing fluorene (see molecular arrangement in Figure 14). Interestingly, these interactions have strong consequences on some electronic characteristics (HOMO energy level) while keeping others unaltered $\left(E_{T}\right)$. Only two examples have pointed out this electronic characteristic to date. ${ }^{6,76} \mathrm{We}$ believe that others will come soon.

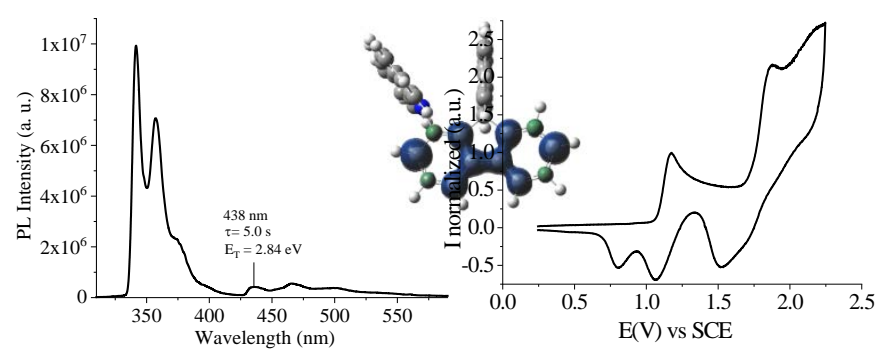

Figure 14: 1-Cbz-SBF. Left. Emission spectrum at $77 \mathrm{~K}\left(2-\mathrm{Me}-\mathrm{THF}, \lambda_{\mathrm{exc}}=300 \mathrm{~nm}\right)$, inset. SDD (isovalue= 0.004). Right. $\mathrm{CV}\left(100 \mathrm{mV} \mathrm{s}^{-1}, \mathrm{CH}_{2} \mathrm{Cl}_{2} / \mathrm{Bu}_{4} \mathrm{NPF}_{6}, 0.2 \mathrm{M}\right)$.

Thus, it has been shown that the first oxidation wave of 1-CbzSBF is strongly shifted towards lower potentials (1.17 V vs SCE, Figure 14-Right) compared to its structurally related analogue fluorene-1-carbazole (1.30 V vs SCE). ${ }^{[72]}$ This electron transfer in 1-Cbz-SBF has been assigned to the oxidation of a cofacial fluorene/carbazole dimer and is the consequence of strong through-space interactions between the fluorene and the carbazole. This work has also shown that the $E_{\mathrm{T}}$ of 1-Cbz-SBF is not deeply influenced by this interaction since the $E_{\mathrm{T}}$ is kept high, $2.84 \mathrm{eV}$ (Figure 14-Left) very close to that of unsubstituted SBF $(2.88 \mathrm{eV})$. This high $E_{\mathrm{T}}$ has been explained by the localization of the triplet exciton, which is exclusively spread out on the substituted fluorene with no contribution of the pendant substituent (Figure 14-Left, inset). Therefore, these studies have shown that the position $\mathrm{C} 1$ is ideal to keep a very high $E_{\mathrm{T}}$ and can increase in the meantime the HOMO energy level through $\pi-\pi$ interactions. This particularity does not exist for the other isomers and appears as an interesting tool, which will be surely used to design host materials for PhOLEDs or more generally other functional materials for electronics.

The last examples we wish to conclude with have shown the high potential of the C1-SBF scaffold. Indeed, in early 2019, our group and that of Jiang have designed highly twisted SBF dimers linked from the C1 position : 1,1"'-(SBF) $2,1, \mathbf{2}^{\prime \prime}-(\mathrm{SBF})_{2}$, $1,3^{\prime \prime}-(\mathrm{SBF})_{2}$ and 1,4"-(SBF) $)_{2}$, Figure 15. These dimers have displayed the highest performance ever reported for PHC materials (EQE of $\sim 23 \%$ for 1 ,3"'-(SBF) $)_{2}$ ) when used as host in blue PhOLEDs. ${ }^{6}$

These C1-linked dimers represent a similar isomers series to the phenyl-SBFs mentioned in section 2, with nevertheless striking differences. Indeed, the strong steric congestion imposed by the two SBF units leads to a different trend to that exposed for phenyl-SBFs. In addition to the nature of the linkage (ortho, meta and para) between two fluorene units, the dihedral angle between them is of chief importance in regards to the electronic coupling/decoupling. ${ }^{39}$ This dihedral angle increases as follows: $54.9^{\circ}$ for $1, \mathbf{2}^{\prime \prime}-(\mathrm{SBF})_{2}, 57.9^{\circ}$ for $\mathbf{1 , 3 ^ { \prime \prime } -}$

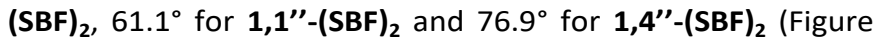
15-Bottom, right). In the case of both $1, \mathbf{2}^{\prime \prime}-(\mathrm{SBF})_{2}$ and $\mathbf{1 , 3} \mathbf{3}^{\prime \prime}-$ $(\mathrm{SBF})_{2}$, the authors noted that this angle is impressively larger than those reported for a non-encumbered phenyl/fluorene linkage, ${ }^{36,39}$ such as in 2-Ph-SBF and in 3-Ph-SBF (Figure 2). ${ }^{39}$ In $1,4^{\prime \prime}-(\mathrm{SBF})_{2}$, the presence of one SBF in ortho position of the other leads to an impressive increasing of the dihedral angle,

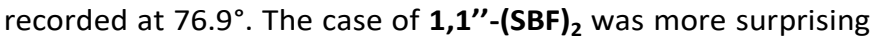
since its dihedral angle $\left(61.1^{\circ}\right)$, despite the strong steric congestion imposed by the two linked $\mathrm{C} 1$ positions was decreased compared to less encumbered 1-Ph-SBF $\left(75.4^{\circ}\right.$, Figure 2). ${ }^{39}$ The explanation provided by the authors is that the angle is lowered in $\mathbf{1 , 1} \mathbf{1}^{\prime \prime}-(\mathbf{S B F})_{\mathbf{2}}$ in order to minimize the $\pi-\pi$ interactions between the two sets of cofacial fluorenes. Thus, in the four C1-linked dimers, the relative position of the SBF fragments provides different molecular arrangements with specific steric hindrances at the origin of their electronic properties.
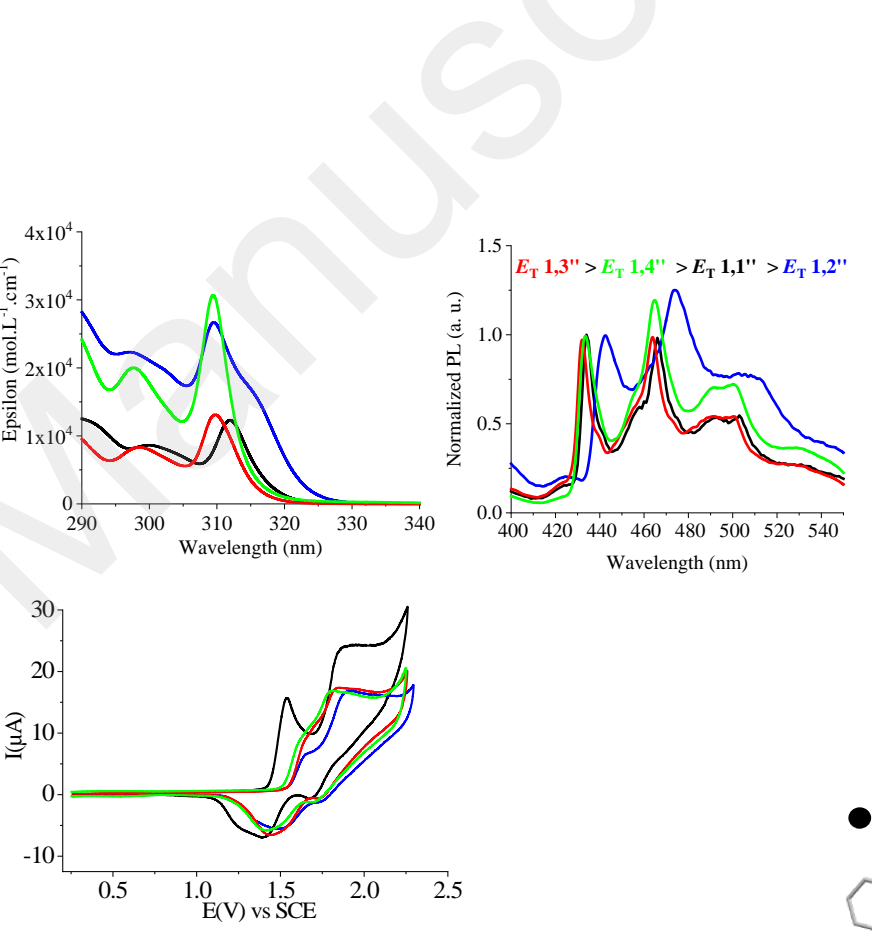

Figure 15. 1,1"-(SBF) $)_{2}, \mathbf{1}^{\prime \prime}$ '-(SBF) $)_{2}, \mathbf{1 , 3} \mathbf{3}^{\prime \prime}-(\mathrm{SBF})_{2}$ and $\mathbf{1 , 4} \mathbf{4}^{\prime \prime}-(\mathrm{SBF})_{2}$. Top. Absorption at room temperature in cyclohexane (Left) and emission at $77 \mathrm{~K}$ in 2-Me-THF (Right, $\left.\lambda_{\text {exc }}=280 \mathrm{~nm}\right)$. Bottom. Left. CV $\left(100 \mathrm{mV} / \mathrm{s}, \mathrm{CH}_{2} \mathrm{Cl}_{2} /\left[\mathrm{Bu}_{4} \mathrm{NPF}_{6}\right] 0.2 \mathrm{M}\right)$. Right. Crystal structures.

From the CVs (Figure 15-Bottom, left), the HOMO energies reported for 1,2 "'-(SBF $)_{2}, 1,3^{\prime \prime}$-(SBF $)_{2}$ and 1,4 "'-(SBF $)_{2}$ were almost identical, $5.95,-5.95$ and $-5.92 \mathrm{eV}$ respectively, Table 2 . Thus, despite their different substitution patterns, the three dimers display very comparable HOMO energy levels, similar to that of their building block SBF $(-5.95 \mathrm{eV})$. Again, this is a different behaviour than that highlighted in the phenyl series (Table 1, the HOMO of 2-Ph-SBF was the highest in the series), indicating the importance of the steric hindrance on the HOMO energy levels. Thus, due to the large 


\begin{tabular}{|c|c|c|c|c|c|}
\hline & $1,1^{\prime \prime}-(\mathrm{SBF})_{2}$ & $1,2^{\prime \prime}-(\mathrm{SBF})_{2}$ & $1,3^{\prime \prime}-(\mathrm{SBF})_{2}$ & $1,4^{\prime \prime}-(\mathrm{SBF})_{2}$ \\
\hline \multicolumn{2}{|c|}{$\begin{array}{l}\lambda_{\mathrm{ABS}}(\varepsilon)^{\mathrm{a}}[\mathrm{nm}] \\
\left(\times 10^{4} \mathrm{~L} \cdot \mathrm{mol}^{-1} \cdot \mathrm{cm}^{-}\right. \\
\left.{ }^{1}\right)\end{array}$} & $\begin{array}{l}300(0.86) \\
312(1.23)\end{array}$ & $\begin{array}{c}297(2.23) \\
309.5(2.67) \\
316(1.54) \\
\end{array}$ & $\begin{array}{l}298.5(0.84) \\
309.5(1.31)\end{array}$ & $\begin{array}{l}297.5(2.00) \\
309.5(3.07)\end{array}$ \\
\hline \multicolumn{2}{|c|}{$\lambda_{E M}{ }^{a}(n m)$} & 325 & 334 & 320 & 326 \\
\hline \multicolumn{2}{|c|}{$\mathrm{QY}^{\mathrm{a}}$} & 0.32 & 0.79 & 0.59 & 0.45 \\
\hline \multicolumn{2}{|l|}{$\tau_{\text {fluo }}[\mathrm{ns}]$} & 4.6 & 2.0 & 4.4 & 4.2 \\
\hline \multicolumn{2}{|c|}{$\mathrm{k}_{\mathrm{r}}\left(\times 10^{7}\right)\left[\mathrm{s}^{-1}\right]$} & 7.0 & 39 & 13 & 11 \\
\hline \multicolumn{2}{|c|}{$\mathrm{k}_{\mathrm{nr}}\left(\times 10^{7}\right)\left[\mathrm{s}^{-1}\right]$} & 15 & 10 & 9.3 & 13 \\
\hline \multicolumn{2}{|c|}{$\tau_{\text {phospho }}[\mathrm{s}]$} & 5.2 & 4.9 & 5.5 & 5.5 \\
\hline \multicolumn{2}{|c|}{ LUMO $(\mathrm{eV})^{\mathrm{b}}$} & -1.84 & -2.11 & -2.01 & -1.90 \\
\hline \multicolumn{2}{|c|}{ HOMO $(\mathrm{eV})^{\mathrm{b}}$} & -5.84 & -5.95 & -5.95 & -5.92 \\
\hline \multirow{2}{*}{$\Delta \mathrm{E}(\mathrm{eV})$} & $\mathrm{Opt}^{\mathrm{c}}$ & 3.88 & 3.83 & 3.94 & 3.92 \\
\hline & $\mathrm{El}^{\mathrm{b}}$ & 4.00 & 3.84 & 3.94 & 4.02 \\
\hline \multicolumn{2}{|l|}{$E_{\mathrm{T}}(\mathrm{eV})^{\mathrm{d}}$} & 2.85 & 2.80 & 2.87 & 2.86 \\
\hline
\end{tabular}

Table 2. Selected electronic properties of SBF dimers

a.in cyclohexane, b. from CVs, c. from UV-Vis spectra, d. from emission spectra in 2-Me-THF at 77K.

dihedral angle between two connected fluorenes, their electronic coupling was fully broken. Despite strongly sterically hindered, $1,1^{\prime \prime}-(\mathrm{SBF})_{2}$ displays a different behaviour with a first wave shifted to a lower potential ( $1.53 \mathrm{~V})$ leading to the highest $\operatorname{HOMO}(-5.84 \mathrm{eV})$ in the series. As exposed above, this is a consequence of the through-space interactions occurring between facing fluorenes. The cathodic explorations reported have revealed a different behaviour. Indeed, the LUMO energy of $\mathbf{1 , 2} \mathbf{2}^{\prime \prime}-(\mathrm{SBF})_{2}$ is the lowest of the series $(-2.11 \mathrm{eV})$, showing a certain degree of coupling between the two connected fluorenes (unlike the HOMO). Thus, for 1,2"$(\mathrm{SBF})_{2}$, the torsion (steric effect) between the two fluorenes seems to have a greater impact on the HOMO energy than on the LUMO energy (that shows influence of the electronic effect of the para linkage). The same effect was also observed for $1,3^{\prime \prime}-(S B F)_{2}$ (LUMO $=-2.01 \mathrm{eV}$ ) but was less pronounced. Thus, this work on C1-linked SBF dimers has shown that the dihedral angle has a different influence on the benzenoidal HOMO/quinoidal LUMO distribution. There is hence a different impact of the linkage and its torsion on the HOMO/LUMO energy level.

In UV-Vis absorption spectroscopy, the four dimers present the same overall structure (Figure 15-Top, left) with the characteristic bands of SBF building block at 300 and $310 \mathrm{~nm}$, but 1,2"-(SBF) displays an additional band at $316 \mathrm{~nm}$ (HOMO $\rightarrow$ LUMO transition), that reflects an electronic coupling between the linked fluorenes. As exposed above, this extension of conjugation is enabled by the para linkage of the C2-substituted SBF, despite the high dihedral angle between them. In the three other isomers, there is no trace of such a low energy band (almost forbidden HOMO-LUMO transition), showing that the $\pi$-conjugation between the two SBF units is largely broken. Thanks to this $\pi$-conjugation breaking, 1,1"-(SBF) ${ }_{2}$, 1,3"-(SBF $)_{2}$ and 1,4"'-(SBF) ${ }_{2}$ all possess a high $E_{\mathrm{T}}$ of 2.85, 2.87 and $2.86 \mathrm{eV}$ respectively (Figure 15-Top, right, Table 2), close to that of unsubstituted $\operatorname{SBF}\left(E_{\mathrm{T}}=2.88 \mathrm{eV}\right)$, as the triplet exciton is efficiently confined on only one fluorene unit. Oppositely, the authors noted that the triplet exciton of $\mathbf{1 , 2} \mathbf{2}^{\prime \prime}-(\mathbf{S B F})_{\mathbf{2}}$ is spread out on two fluorenes, which decreases the $E_{\mathrm{T}}$ to $2.80 \mathrm{eV}$, a value nevertheless very high for a 2 -substituted $S B F .^{3}$ When incorporated as host in blue PhOLEDs, the $\mathrm{EQE}_{\max }$ obtained were all very high, $20.1 \%$, $20.3 \%, 22.9 \%$ and $19.1 \%$ for $\mathbf{1 , 1 "} \mathbf{1}^{\prime \prime}(\mathrm{SBF})_{2}, \mathbf{1 , 2} \mathbf{2}^{\prime \prime}-(\mathrm{SBF})_{2}, \mathbf{1 , 3} \mathbf{3}^{\prime \prime}-(\mathrm{SBF})_{2}$ and 1,4 "'-(SBF $)_{2}$ respectively. The turn-on voltages of all the devices were also found to be below $3 \mathrm{~V}$, a low value for blue emission translating an excellent charge injection in such PHC systems. The

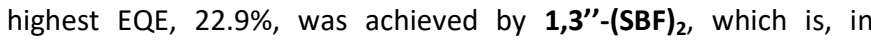
September 2019, the highest value for a PHC host ever reported in the literature. ${ }^{6}$ There is no doubt that the C1-SBF scaffold is at the origin of this very high performance. 
Table 3. Selected OLEDs performances using SBF compounds as hosts

\begin{tabular}{|c|c|c|c|c|c|c|}
\hline Host & Device Structure ${ }^{a, b}$ & $\begin{array}{l}V_{\text {on }} \\
\text { (V) }\end{array}$ & $\begin{array}{l}\text { EQE } \\
(\%)^{c}\end{array}$ & $\begin{array}{c}\mathrm{CE} \\
(\mathrm{Cd} / \mathrm{A})^{\mathrm{C}}\end{array}$ & $\begin{array}{c}\mathrm{PE} \\
(\mathrm{Lm} / \mathrm{W})^{\mathrm{c}}\end{array}$ & Ref \\
\hline \multicolumn{7}{|c|}{ Green PhOLED } \\
\hline 4-DBF-SBF & ITO/MoO $3 / \mathrm{NPB} / \mathrm{TCTA} /$ Host + Ir(ppy) ${ }_{2}$ (acac) 8\%/TPBi/Liq/Al & 4.9 & 21.2 & 64.4 & 49.7 & 68 \\
\hline 4-Ph(OMe $)_{3}$-SBF & ITO/CuPc/NPB/TCTA/Host +Ir(ppy) $)_{3}$ 10\% /TPBi/LiF/AI & 4.3 & 20.2 & 78.0 & 48.1 & 33 \\
\hline 4-PhCz-SBF & ITO/CuPc/NPB/TCTA/Host + Ir(ppy $)_{3} 10 \% / \mathrm{TPBi} / \mathrm{LiF} / \mathrm{Al}$ & 3.7 & 17.5 & 67.9 & 45.4 & 33 \\
\hline 4-PPI-SBF & $\mathrm{ITO} / \mathrm{MoO}_{3} / \mathrm{TAPC} /$ Host $+\operatorname{lr}(\text { ppy })_{2}$ (acac) $8 \% / \mathrm{TPBi} / \mathrm{LiF} / \mathrm{Al}$ & 2.8 & 16.8 & 64.1 & 67.9 & 72 \\
\hline 4-DBT-SBF & $\mathrm{ITO} / \mathrm{MoO}_{3} / \mathrm{NPB} / \mathrm{TCTA} /$ Host $+\operatorname{Ir}(\text { ppy })_{2}$ (acac) $8 \% / \mathrm{TPBi} / \mathrm{Liq} / \mathrm{Al}$ & - & 16.3 & 62.0 & 45.9 & 67 \\
\hline 4-POPh ${ }_{2}$-SBF & ITO/PEDOT:PSS /Host + Ir(ppy) ${ }_{3} 10 \% 100 \mathrm{~nm} / \mathrm{LiF} / \mathrm{Al}$ & 3.3 & 13.3 & 50.2 & 29.8 & 63 \\
\hline \multicolumn{7}{|c|}{ Green TADF OLED } \\
\hline $3,4^{\prime \prime}-(\mathrm{SBF})_{2}$ & ITO/HAT-CN/TAPC/Host + 4CzIPN 8\%/TmPyPB/Liq/Al & 2.8 & 22.3 & 69.0 & 51.5 & 36 \\
\hline $\left.3,3^{\prime \prime}-\mathrm{SBF}\right)_{2}$ & ITO/HAT-CN/TAPC/Host + 4CzIPN 8\%/TmPyPB/Liq/Al & 2.6 & 20.6 & 65.0 & 51.2 & 36 \\
\hline \multicolumn{7}{|c|}{$\begin{array}{ll}\text { Blue PhOLED } \\
\end{array}$} \\
\hline $1,3 “-(\mathrm{SBF})_{2}$ & ITO/ HAT-CN/TAPC/TCTA/mCP/Host + Flrpic 15\%/TmPyPB/Liq/Al & 2.9 & 22.9 & 45.5 & 36.3 & 6 \\
\hline $3,4^{\prime \prime}-(\mathrm{SBF})_{2}$ & ITO/HAT-CN/TAPC/Host + Flrpic 8\% /TmPyPB/Liq/Al & 3.0 & 22.0 & 44.5 & 36.5 & 36 \\
\hline $1,2^{\prime \prime}-(\mathrm{SBF})_{2}$ & ITO/HAT-CN/TAPC/TCTA/mCP/Host + Flrpic 15\%/TmPyPB/Liq/Al & 2.7 & 20.3 & 38.5 & 34.5 & ${ }^{6}$ \\
\hline $1,1^{\prime \prime}-(\mathrm{SBF})_{2}$ & ITO/HAT-CN/TAPC/TCTA/mCP/Host + Flrpic 15\%/TmPyPB/Liq/Al & 2.9 & 20.1 & 40.3 & 32.9 & ${ }^{6}$ \\
\hline 3-(N-Ph-Cbz)SBF & ITO/HAT-CN/TAPC/Host + Flrpic 5\%/TmPyPB/Liq/Al & 3.6 & 19.7 & 44.5 & 38.7 & 75 \\
\hline $1,4^{\prime \prime}-(\mathrm{SBF})_{2}$ & ITO/HAT-CN/TAPC/TCTA/mCP/Host + Flrpic 15\%/TmPyPB/Liq/Al & 2.9 & 19.1 & 38.5 & 32.7 & ${ }^{6}$ \\
\hline 3-diNCbz-SBF & ITO/HAT-CN/TAPC/Host + Flrpic 8\% /TmPyPB/Liq/Al & 3.2 & 18.1 & 41.5 & 40.1 & 38 \\
\hline 3-(N-Ph-Cbz)SBF & ITO/HAT-CN/TAPC/Host + Flrpic 5\%/TmPyPB/Liq/Al & 3.7 & 18.1 & 41.0 & 34.7 & 75 \\
\hline 4-POPh ${ }_{2}$-SBF & ITO/PEDOT:PSS/NPB/mCP/Host + FIrpic 10\%/4-POPh ${ }_{2}$-SBF/LiF/Al & - & 17.5 & 35.6 & 24.7 & 65 \\
\hline 4-POPh ${ }_{2}$-SBF & ITO/PEDOT:PSS/NPB/mCP/Host + Flrpic 10\%/BCP/Alq $/$ /LiF/Al & 3.3 & 17.2 & 35.3 & 26.0 & 65 \\
\hline 3-POPh 2 -SBF & ITO/MoO $: \mathrm{mCP}, 15 \% / \mathrm{mCP} /$ Host + Flr6 8\% /TmPyPB/Liq/Al & 3.8 & 13.6 & 28.5 & 23.7 & 45 \\
\hline $3,3^{\prime \prime}-(\mathrm{SBF})_{2}$ & ITO/HAT-CN/TAPC/Host + Flrpic 8\%/TmPyPB/Liq /AI & 2.8 & 11.4 & 23.0 & 19.7 & 36 \\
\hline 4-DBT-SBF & $\mathrm{ITO} / \mathrm{MoO}_{3} / \mathrm{NPB} / \mathrm{TCTA} /$ Host + Flrpic $8 \% / \mathrm{TPBi} / \mathrm{Liq} / \mathrm{Al}$ & - & 10.3 & 23.5 & 16.6 & 67 \\
\hline 3-POPh-(SBF) $)_{2}$ & $\mathrm{ITO} / \mathrm{MoO}_{3}: \mathrm{mCP}, 15 \mathrm{wt} \% / \mathrm{mCP} /$ Host + FIr6 8\%/TmPyPB/Liq/Al & 4.1 & 10.2 & 22.0 & 18.5 & 45 \\
\hline 4-Ph(OMe) $)_{3}$-SBF & ITO/CuPc/NPB/TCTA/Host + Flrpic 20\% /TPBi/LiF/Al & 4.2 & 9.6 & 24.2 & 13.9 & 33 \\
\hline 4-DBF-SBF & ITO/MoO $3 / \mathrm{NPB} / \mathrm{TCTA} /$ Host + Flrpic 8\% /TPBi/Liq/Al & 5.6 & 7.5 & 22.2 & 16.4 & 68 \\
\hline 4-PhCz-SBF & ITO/CuPc/NPB /TCTA/Host + Flrpic: 17\% /TPBi/LiF/Al & 3.7 & 6.7 & 18.0 & 11.0 & 33 \\
\hline 1-Ph-SBF & ITO/CuPc/NPB /TCTA/Host + Flrpic: 5\%/TmPyPB/LiF/Al & 4.7 & 5.9 & 15.9 & 5.9 & \\
\hline 4-Ph-SBF & ITO/CuPc/NPB /TCTA/Host + Flrpic: 5\% /TmPyPB/LiF /Al & 4.0 & 5.5 & 14.1 & 5.8 & 39 \\
\hline 3-Ph-SBF & ITO/CuPc/NPB/TCTA/Host + Flrpic: 5\% /TmPyPB/LiF/Al & 4.9 & 4.7 & 12.8 & 4.4 & \\
\hline \multicolumn{7}{|c|}{$\begin{array}{ll}\text { Blue TADF } \\
\end{array}$} \\
\hline 3-PhTriaZCbz-SBF ${ }^{d}$ & ITO/HAT-CN/TAPC/mCP/DPEPO(host) + 3-PhTriaZCbz-SBF 30\% /TmPyPB/Liq/Al & 4.3 & 10.6 & 15.0 & 11.0 & 74 \\
\hline \multicolumn{7}{|c|}{ White PhOLED } \\
\hline 3-diNCbz-SBF & $\begin{array}{l}\text { ITO/HAT-CN/TAPC/Host + Flrpic:PO-01 8\%:0.5 \%/TmPyPB:Li 1.2\%/Bphen:Li 1.2\%/ } \\
\text { HAT-CN/TAPC/Host + Ir(ppy) } 2 \text { (acac):Ir(MDQ) } 2 \text { acac 6\%:2\%/TmPyPB/Liq /Al }\end{array}$ & 6.1 & 40.0 & 110.5 & 57.1 & 38 \\
\hline $3,4^{\prime \prime}-(\mathrm{SBF})_{2}$ & ITO/HAT-CN/TAPC/Host + Flrpic:PO-01/TmPyPB/Liq/Al & 2.6 & 25.3 & 71.0 & 66.5 & 36 \\
\hline 3-diNCbz-SBF & ITO/HAT-CN/TAPC/Host + Flrpic 8\% /Host + PO-01 6\%/TmPyPB /Liq /AI & 3.1 & 21.3 & 67.2 & 66.1 & 38 \\
\hline 3-diNCbz-SBF & $\begin{array}{l}\text { ITO/HAT-CN/TAPC/Host + Flrpic } 8 \% / \text { Host + Ir(ppy) }{ }_{2}(\text { acac): Ir(MDQ })_{2} \text { acac } \\
8: 2 \% / \text { TmPyPB /Liq/Al }\end{array}$ & 3.1 & 19.8 & 50.0 & 48.9 & \\
\hline 3-(3-PhCbz) SBF & 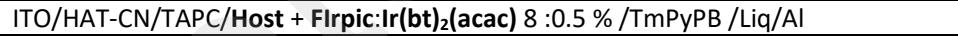 & 3.5 & 19.1 & 53.0 & 48.0 & 75 \\
\hline 3-(N-Ph-Cbz)SBF & 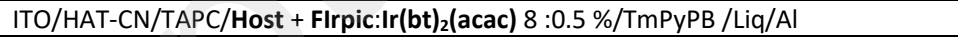 & 3.7 & 18.2 & 50.5 & 40.4 & \\
\hline 4-DBT-SBF & ITO/MoO $/ \mathrm{MPB}_{3} / \mathrm{TCTA} /$ Host + PO-01 3\% (2nm)/Host + Flrpic 8\%(18nm)/TPBi/Liq /AI & 6.2 & 16.9 & 52.3 & 33.1 & \\
\hline 4-DBT-SBF & $\begin{array}{l}\text { ITO/MoO } / \mathrm{MPB}_{3} / \mathrm{TCTA} / \text { Host + PO-01 3\% }(1.5 \mathrm{~nm}) / \text { Host + Flrpic } 8 \%(18.5 \mathrm{~nm}) / \mathrm{TPBi} / \mathrm{Liq} \\
\text { /Al }\end{array}$ & 6.2 & 16.1 & 48.8 & 32.4 & 67 \\
\hline 4-DBT-SBF & ITO/MoO $/ \mathrm{MPB}_{3} / \mathrm{TCTA} /$ Host + PO-01 3\% (1nm)/Host + Flrpic 8\%(19nm)/TPBi/Liq /AI & 6.3 & 14.6 & 42.3 & 26.9 & \\
\hline 4-DBT-SBF & $\begin{array}{l}\text { ITO/MoO } / \text { /NPB/TCTA/Host + PO-01 3\% }(0.5 \mathrm{~nm}) / \text { Host + Flrpic } \\
8 \%(19.5 \mathrm{~nm}) / \mathrm{TPBi} / \mathrm{Liq} / \mathrm{Al}\end{array}$ & 6.5 & 13.1 & 35.8 & 24.0 & \\
\hline
\end{tabular}

a. regarding the thickness of the different layers, see details in the related publications

b. ITO: Indium-Tin Oxide, CuPc:copper phtalocyanine (hole-injecting layer), $\mathrm{MoO}_{3}$ : molybdenum trioxide (hole-injecting layer), HAT-CN : 1,4,5,8,9,11-hexatriphenylenehexacarbonitrile (hole-injecting layer), PEDOT:PSS: Poly(3,4-ethylenedioxythiophene)-poly(styrenesulfonate) (hole-injecting layer) TAPC: 1,1 -bis[4-[N,N-di(ptolyl)amino]phenyl]cyclohexane (hole-transporting and electron-blocking layer), NPB: $N, N^{\prime}$-di(1-naphtyl)- $N, N^{\prime}$-diphenyl-[1,10-biphenyl]-4,4'-diamine (hole-transporting layer), mCP: 1,3-Bis(N-carbazolyl)benzene (hole transport and hole injecting layer), TCTA: 4,4',4"-tris(carbazole-9-yl)triphenylamine (electron and exciton blocking layer), TPBi: 1,3,5Tris(1-phenyl-1H-benzimidazol-2-yl)benzene (electron-transporting / hole-blocking layer), TmPyPB : 1,3,5-tri[(3-pyridyl)-phen-3-yl]benzene (electron-transporting and holeblocking layer), BCP: bathocuproine: 2,9-Dimethyl-4,7-diphenyl-1,10-phenanthroline (Electron-transport layer, Electron-injection layer, Hole-blocking layer), Liq:8hydroxyquinolinato-lithium (electron-injecting layer), LiF: Lithium fluoride, Al: aluminum (cathode), $\operatorname{Ir}($ ppy) 2 (acac): Bis[2-(2-pyridinyl-N)phenyl-C](acetylacetonato)iridium(III) (green phosphorescent emitter), Ir(ppy) $)_{3}$ : tris[2-phenylpyridinato-C2,N]iridium(III) (green phosphorescent emitter), 4CzIPN : 2,4,5,6-tetra(9H-carbazol-9-yl)isophtalonitrile (green TADF emitter). FIrpic: bis[2-(4,6-difluorophenyl)pyridinato-C2,N](picolinato)iridium(III) (blue phosphorescent emitter), FIr6: Iridium(III) bis(4',6'difluorophenylpyridinato)tetrakis(1-pyrazolyl)borate (blue phosphorescent emitter), PO-01: (acetylacetonato)bis[2-(thieno[3,2-c]pyridin-4-yl)phenyl]iridium(III) (orange phosphorescent emitter), $\operatorname{Ir}(\mathrm{bt})_{2}(\mathrm{acac})$ : Bis(2-benzo[b]thiophen-2-ylpyridine)(acetylacetonate)iridium(III) (red phosphorescent emitter), Ir(MDQ) ${ }_{2}$ acac: Bis(2-methyldibenzo[f,h]quinoxaline)(acetylacetonate)iridium (III) (red phosphorescent emitter), DPEPO : bis-(2-(diphenylphosphino)phenyl)eher oxide (host for blue TADF emitter), -: not available.

c. maximum values

d. used 


\section{Conclusions}

SBF based compounds constitute an important class of OSCS and have undergone a great development in the last twenty years. However, the most studied isomer is the 2-substituted SBF isomer and the other positional isomers have only appeared in the literature in the last ten years. These isomers have allowed to investigate new directions regarding the use of the SBF scaffold: high $E_{\mathrm{T}}$ host materials to host blue phosphors in PhOLEDs and TADF OLEDs. Thus, many highly efficient host materials for PhOLEDs have been constructed using 1-, 3- or 4-substituted SBF scaffolds and have allowed significant breakthroughs in the field. Indeed, the SBF substitution pattern allows to disrupt or completely break the electronic coupling (by electronic and/or steric parameters) between the SBF fragment and its linked substituent. This characteristic is essential to maintain a wide bandgap and a high $E_{\mathrm{T}}$ which are two crucial characteristics in the design of host materials for blue PhOLEDs. In addition, the spiro bridge strongly increases the thermal/morphological properties compared to non-bridge analogues, which are essential for a device's stability in time.

Today, the four positional isomers of SBF have been introduced in the literature but all their properties have surely not yet been highlighted. In this work, we show how the combination of electronic and steric parameters drive all the electrochemical and photophysical properties. The most recent family, 1-substituted SBFs core, seems to be the most appealing for electronic applications as it has already led to the most efficient PHC-based PhOLEDs reported to date. ${ }^{6}$ Organic electronics is a very competitive research field worldwide and the 1-substituted SBF scaffold, in less than two years, has already shown a true potential. Each isomer displays its own electronic characteristics and from a structural point of view, the SBF platform appears as a remarkable playground for chemists. An important question arises: What is the best position to design host materials for PhOLEDs or TADF OLEDs? It is still difficult to answer this question with a complete certitude but the most recent studies ${ }^{6}$ seem to show that $\mathrm{C} 1$, which gathers the structural and electronic characteristics of C4 and C3, is the most efficient. If very high performances have been reached with $\mathrm{C} 1$ linked SBF PHC, however, until now functional materials (incorporating electron-rich and/or electron-poor units) have still not been investigated (only one example exists but without a device incorporation ${ }^{76}$ ). In addition and as far as we know, the C1-SBF scaffold has not been used yet to construct hosts for TADF OLEDs. We believe that these materials will be investigated soon. A very recent study published in May 2019 by Fung, Fan and their coworkers has also shown that the position $\mathrm{C} 1$ of structurally related fluorenones leads to higher red PhOLED performances than the other regioisomers, confirming the potential of this position. $^{78}$

Another point has not yet been investigated considering these isomers: the geometry. Indeed, the SBF substitution pattern has only been used to modulate the electronic coupling between the substituent and the SBF, but not for the geometry itself and its consequences on the (supra) molecular assemblies. Our group has recently started to investigate this strategy, taken benefit of the particular geometry of a 1substituted fluorene. ${ }^{79}$ Indeed, in spirofluorenequinolinophenothiazine compounds ${ }^{79}$ (such as $\mathbf{3 3}$, substituted at C3 of the fluorene, Figure 16-Top), the phenothiazine can move from one side of the fluorene to the other through a structural reorganization of the acridine, much like a wing flapping. By incorporating a phenyl ring at $\mathrm{C} 1$ of the fluorene (such as in 34, Figure 16-Bottom), the flipping of the phenothiazine is prevented providing an interesting diasterocontrol.

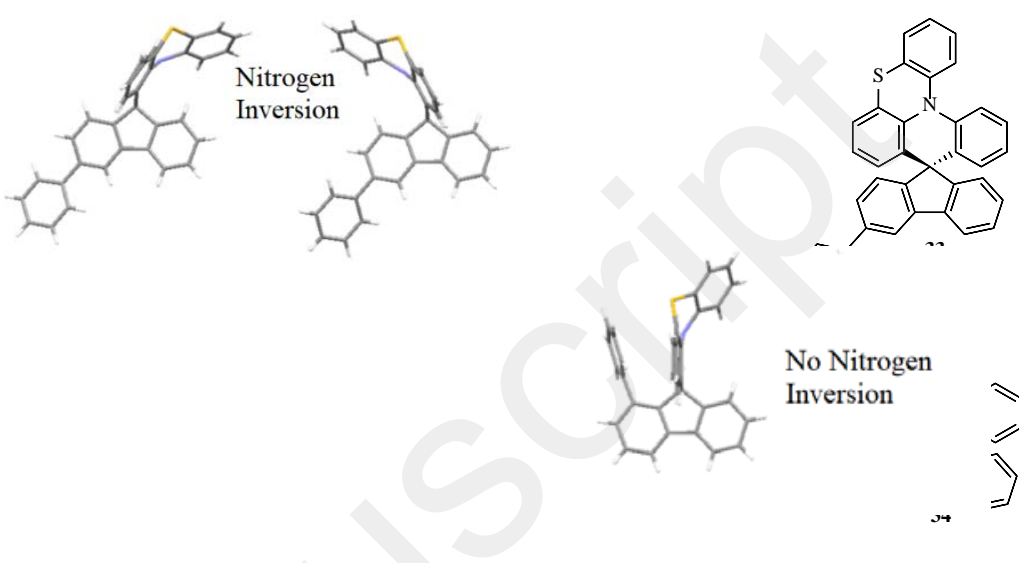

Figure 16. X-Ray structures (Left) and molecular structure of two fluorenespiroquinolinophenothiazine derivatives substituted at C3 (Top) or at C1 (Bottom)

We are convinced that other strategies, which will take advantage from the SBF geometry will be developed in the future. For example, the different substitution patterns of the SBF core may allow to construct different molecular assemblies for catalysis or metal organic frameworks. Thus, the different substitutions of the SBF core offer chemists a formidable tool to construct spiro configured molecules with different shapes. The recent examples of SBF metalloaromatics ${ }^{80}$ or high efficiency bipolar host masterials ${ }^{81}$ could take advantage from the SBF isomerism.

Finally, we also believe, that another interesting direction for the future will consist in introducing not only one substituent on the SBF fragment but two, three or four. This will lead to highly elaborate 3D materials with singular solid state supramolecular properties, which could even display chiral properties. In any event, we are convinced that the SBF family will remain a central scaffold in the future of Organic Electronics.

\section{Conflicts of interest}

There are no conflicts to declare.

\section{Acknowledgements}

The authors would like to highly thank all their coworkers in the group, which have allowed over the years the development of these new generations of SBFs: F. Lucas, Drs S. Thiery, O. Jeannin, J.D. Peltier and C. Quinton (Rennes). Other coworkers and research groups have also contribute to the development of this field. We wish to particularly thank Drs R. Métivier, B. Geffroy and D. Tondelier (Paris Saclay), E. Jacques (Rennes) and Prof Z. Jiang (Suzhou). We also thank the CINES (Montpellier $\mathrm{N}^{\circ} 2019$ A0060805032), the ANR (14-CE05-0024) for a PhD grant (LJS), the ANR (11-BS07-020-01), the Région Bretagne and the ADEME for financial support.

\section{Notes and references}


1.C. Poriel and J. Rault - Berthelot, Acc. Chem. Res., 2018, 51, 1818.

2.T. P. I. Saragi, T. Spehr, A. Siebert, T. Fuhrmann-Lieker and J. Salbeck, Chem. Rev., 2007, 107, 1011.

3.C. Poriel and J. Rault-Berthelot, J. Mater. Chem. C, 2017, 5, 3869.

4.Z. Ma, P. Sonar and Z.-K. Chen, Curr. Org. Chem., 2010, 18, 2039.

5.X. Yang, X. Xu and G. Zhou, J. Mater. Chem. C, 2015, 3, 913.

6.L. J. Sicard, H.-C. Li, Q. Wang, X.-Y. Liu, O. Jeannin, J. Rault-Berthelot, L.-S

Liao, Z.-Q. Jiang and C. Poriel, Angew. Chem. Int. Ed., 2019, 58, 3848.

7.R. S. Sanchez and E. Mas-Marza, Sol. Energy Mater. Sol. Cells, 2016, 158, Part 2, 189.

8.N.-G. Park, Mater. Today, 2015, 18, 65.

9.N. Berton, R. Nakar and B. Schmaltz, Synth. Met., 2019, 252, 91.

10.J. Yi, Y. Wang, Q. Luo, Y. Lin, H. Tan, H. Wang and C.-Q. Ma, Chem Commun., 2016, 52, 1649.

11.K. C. Song, R. Singh, J. Lee, D. H. Sin, H. Lee and K. Cho, J. Mater. Chem. C 2016, 45, 10610.

12.X.-F. Wu, W.-F. Fu, Z. Xu, M. Shi, F. Liu, H.-Z. Chen, J.-H. Wan and T. P. Russell, Adv. Funct. Mat., 2015, 25, 5954.

13.S. Li, W. Liu, M. Shi, J. Mai, T.-K. Lau, J. Wan, X. Lu, C.-Z. Li and H. Chen, Energy Environ. Sci, 2016, 9, 604.

14.Y. Hu, D. Wang, M. Baumgarten, D. Schollmeyer, K. Müllen and A. Narita Chem. Comm., 2018, 54, 13575.

15.S. Kudruk, E. Villani, F. Polo, S. Lamping, M. Körsgen, H. F. Arlinghaus, F. Paolucci, B. J. Ravoo, G. Valenti and F. Rizzo, Chem. Comm., 2018, 54, 4999.

16.J. Jalkh, S. Thiery, J.-F. Bergamini, P. Hapiot, C. Poriel and Y. R. Leroux, J. Phys. Chem. C, 2017, 121, 14228.

17.F. Schlüter, K. Riehemann, N. S. Kehr, S. Quici, C. G. Daniliuc and F. Rizzo, Chem. Comm., 2018, 54, 642.

18.J.-H. Xie and Q.-L. Zhou, Acc. Chem. Res., 2008, 41, 581.

19.C. Poriel, Y. Ferrand, P. Le Maux, J. Rault-Berthelot and G. Simonneaux Synth. Met., 2008, 158, 796.

20.C. Poriel, Y. Ferrand, P. Le Maux, J. Rault-Berthelot and G. Simonneaux Tetrahedron Lett., 2003, 44, 1759.

21.C. Poriel, Y. Ferrand, P. Le Maux, J. Rault-Berthelot and G. Simonneaux Inorg. Chem., 2004, 43, 5086.

22.C. Poriel, Y. Ferrand, S. Juillard, P. Le Maux and G. Simonneaux, Tetrahedron, 2004, 60, 145.

23.Y. Ferrand, C. Poriel, P. Le Maux, J. Rault-Berthelot and G. Simonneaux Tetrahedron Asymmetry, 2005, 16, 1463.

24.C. Poriel, Y. Ferrand, P. Le Maux, J. Rault-Berthelot and G. Simonneaux Chem. Commun., 2003, 1104.

25.F. Moreau, N. Audebrand, C. Poriel, V. Moizan-Baslé and J. Ouvry, J. Mater. Chem., 2011, 21, 18715.

26.X. Fang, L. Wang, X. He, J. Xu and Z. Duan, Inorg. Chem., 2018, 57, 1689.

27.K. S. Yook and J. Y. Lee, Adv. Mater., 2012, 24, 3169.

28.K. S. Yook and J. Y. Lee, Adv. Mater., 2014, 26, 4218.

29.R. Mertens, The OLED Handbook: A Guide to OLED Technology, Industry \& Market, 2019.

30.C. Fan, Y. Chen, P. Gan, C. Yang, C. Zhong, J. Qin and D. Ma, Org. Lett. 2010, 12, 5648

31.Z. Jiang, H. Yao, Z. Zhang, C. Yang, Z. Liu, Y. Tao, J. Qin and D. Ma, Org Lett., 2009, 11, 2607.

32.S. Thiery, D. Tondelier, C. Declairieux, B. Geffroy, O. Jeannin, R. Métivier J. Rault-Berthelot and C. Poriel, J. Phys. Chem. C, 2015, 119, 5790.

33.C. Quinton, S. Thiery, O. Jeannin, D. Tondelier, B. Geffroy, E. Jacques, J. Rault-Berthelot and C. Poriel, ACS Appl. Mater. Interfaces., 2017, 9, 6194.

34.S. Thiery, C. Declairieux, D. Tondelier, G. Seo, B. Geffroy, O. Jeannin, R. Métivier, J. Rault-Berthelot and C. Poriel, Tetrahedron, 2014, 70, 6337.

35.S. Thiery, D. Tondelier, C. Declairieux, G. Seo, B. Geffroy, O. Jeannin, J. Rault-Berthelot, R. Métivier and C. Poriel, J. Mater. Chem. C, 2014, 2, 4156.

36.L.-S. Cui, Y.-M. Xie, Y.-K. Wang, C. Zhong, Y.-L. Deng, X.-Y. Liu, Z.-Q. Jiang and L.-S. Liao, Adv. Mater., 2015, 27, 4213.

37.M.-M. Xue, Y.-M. Xie, L.-S. Cui, X.-Y. Liu, X.-D. Yuan, Y.-X. Li, Z.-Q. Jiang and L.-S. Liao, Chem. Eur. J., 2016, 22, 916.

38.Y. Liu, L.-S. Cui, X.-B. Shi, Q. Li, Z.-Q. Jiang and L.-S. Liao, J. Mater. Chem. C, 2014, 2, 8736 .

39.L. Sicard, C. Quinton, J.-D. Peltier, D. Tondelier, B. Geffroy, R. Métivier, O. Jeannin, J. Rault-Berthelot and C. Poriel, Chem. Eur. J., 2017, 23, 7719.

40.J.-D. Peltier, B. Heinrich, B. Donnio, O. Jeannin, J. Rault-Berthelot, E. Jacques and C. Poriel, J. Mater. Chem. C, 2018, 6, 13197
41.S. Bebiche, P. Cisneros-Perez, T. Mohammed-Brahim, M. Harnois, J. Rault - Berthelot, C. Poriel and E. Jacques, Mater. Chem. Front., 2018, 2, 1631.

42.J.-D. Peltier, B. Heinrich, B. Donnio, E. Jacques, J. Rault-Berthelot and C. Poriel, ACS Appl. Mater. Interfaces, 2017, 9, 8219.

43.M. Romain, C. Quinton, D. Tondelier, B. Geffroy, O. Jeannin, J. RaultBerthelot and C. Poriel, J. Mater. Chem. C, 2016, 4, 1692.

44.R. G. Clarkson and M. Gomberg, J. Am. Chem. Soc., 1930, 52, 2881.

45.L.-S. Cui, S.-C. Dong, Y. Liu, M.-F. Xu, Q. Li, Z.-Q. Jiang and L.-S. Liao, Org. Electron., 2013, 14, 1924.

46.C. Poriel, F. Barrière, J. Rault - Berthelot and D. Thirion, Chem. Eur. J., 2019, 25, 7740.

47.C. Poriel, F. Barrière, D. Thirion and J. Rault-Berthelot, Chem. Eur. J., 2009, 15, 13304

48.N. Fomina, S. E. Bradforth and T. E. Hogen-Esch, Macromolecules, 2009, 42, 6440 .

49.N. A. Van Dantzig, D. H. Levy, C. Vigo and P. Piotrowiak, J. Chem. Phys., 1995, 103, 4894.

50.N. Kharasch and T. C. Bruice, J. Am. Chem. Soc., 1951, 73, 3240.

51.E. H. Huntress, K. Pfister and K. H. T. Pfister, J. Am. Chem. Soc., 1942, 64, 2845.

52.S. R. D. George, L. T. Scott and J. B. Harper, Polycyclic Aromatic Compounds, 2016, 36, 697.

53.M. Hedidi, W. Erb, F. Lassagne, Y.S. Halauko, O.A. Ivashkevich, V.E. Matulis, T. Roisnel, G. Bentabed-Ababsa and F. Mongin, RSC Adv., 2016, 6, 63185

54.D. Velasco and Z. Yu, Tetrahedron Lett., 1999, 3229.

55.X.-Y. Chen, S. Ozturk and E. J. Sorensen, Org. Lett., 2017, 19, 1140.

56.S. Karaburnaliev, M. Baumgarten, N. Tyutyulkov and K. Müllen, J. Phys. Chem., 1994, 98, 11892.

57.S. Y. Hong, D. Y. Kim, C. Y. Kim and R. Hoffmann, Macromolecules, 2001, 34, 6474.

58.P. Guiglion and M.A. Zwijnenburg, Phys.Chem.Chem.Phys., 2015, 17,17854

59.C. S. Hartley, Acc. Chem. Res., 2016, 49, 646.

60.J. He, J. L. Crase, S. H. Wadumethrige, K. Thakur, L. Dai, S. Zou, R. Rathore and C. S. Hartley, J. Am. Chem. Soc., 2010, 132, 13848.

61.H.-H. Huang, C. Prabhakar, K.-C. Tang, P.-T. Chou, G.-J. Huang and J.-S. Yang, J. Am. Chem. Soc., 2011, 133, 8028.

62.M. Romain, S. Thiery, A. Shirinskaya, C. Declairieux, D. Tondelier, B. Geffroy, O. Jeannin, J. Rault-Berthelot, R. Métivier and C. Poriel, Angew. Chem. Int. Ed., 2015, 54, 1176.

63.S. Thiery, D. Tondelier, B. Geffroy, E. Jacques, M. Robin, R. Métivier, O. Jeannin, J. Rault-Berthelot and C. Poriel, Org. Lett., 2015, 17, 4682.

64.S. Thiery, B. Heinrich, B. Donnio, C. Poriel and F. Camerel, J. Phys. Chem. C, 2015, 119, 10564.

65.S. E. Jang, C. W. Joo, S. O. Jeon, K. S. Yook and J. Y. Lee, Org. Electron., 2010, 11, 1059.

66.C. Poriel, J. Rault-Berthelot, S. Thiery, C. Quinton, O. Jeannin, U. Biapo, B. Geffroy and D. Tondelier, Chem. Eur. J., 2016, 22, 17930.

67.S.-C. Dong, C.-H. Gao, X. D. Yuan, L.-S. Cui, Z.-Q. Jiang, S.-T. Lee and L. S. Liao, Org. Electron., 2013, 14, 902.

68.S.-C. Dong, C.-H. Gao, Z.-H. Zhang, Z.-Q. Jiang, S.-T. Lee and L. S. Liao, Phys. Chem. Chem. Phys., 2012, 14, 14224.

69.J.-F. Wang, J.-K. Feng, A.-M. Ren and L. Yang, Chin. J. Chem., 2005, 23, 1618.

70.D. Thirion, C. Poriel, R. Métivier, J. Rault-Berthelot, F. Barrière and O. Jeannin, Chem. Eur. J., 2011, 17, 10272.

71.R. P. Kaiser, J. Mosinger, I. Císařová and M. Kotora, Org. Biomol. Chem., 2017, 15, 6913.

72.Z.-Y. Wang, J.-W. Zhao, B. Liu, C. Cao, P. Li, Q.-X. Tong and S.-L. Tao, Dyes Pigm., 2019, 163, 213.

73.I. Bulut, P. Chavez, S. Fall, S. Mery, B. Heinrich, J. Rault-Berthelot, C. Poriel, P. Leveque and N. Leclerc, RSC Adv., 2016, 6, 25952.

74.J.-J. Liang, Y. Li, Y. Yuan, S.-H. Li, X.-D. Zhu, S. Barlow, M.-K. Fung, Z.-Q. Jiang, S. R. Marder and L.-S. Liao, Mater. Chem. Front., 2018, 2, 917.

75.L. Ding, S. Du, L.-S. Cui, F. Zhang and L.-S. Liao, Org. Electron.,2016, 37, 108

76.L. J. Sicard, C. Quinton, F. Lucas, O. Jeannin, J. Rault-Berthelot and C. Poriel, J. Phys. Chem. C, 2019, 123, 19094. 
77.N. A. Van Dantzig, D. H. Levy, C. Vigo and P. Piotrowiak, J. Chem. Phys., 1995, 103, 4894.

78.X. Fei, Y.-J. Zhang, X.-Y. Liu, M.-K. Fung and J. Fan, Tetrahedron, 2019, 75,

2664

79.C. Quinton, L. Sicard, O. Jeannin, N. Vanthuyne and C. Poriel, Adv. Funct. Mat., 2018, 28, 180340.

80.V. C. Arias-Coronado, R. Pereira-Cameselle, A. Ozcelik, M. Talavera, Á. Peña-Gallego, J. L. Alonso-Gómez and S. Bolaño, Chem. Eur. J., 10.1002/chem.201903213.

81. F. Lucas, O. A. Ibraikulov, C. Quinton, L. Sicard, T. Heiser, D. Tondelier B. Geffroy, N. Leclerc, J. Rault-Berthelot and C. Poriel, Adv. Opt. Mat. 2019 10.1002/adom.201901225 